\title{
Recent Progress in Cathode Materials for Thermal Batteries
}

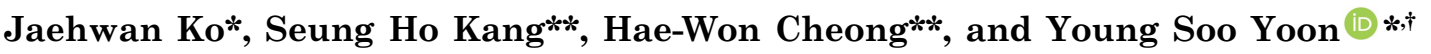 \\ *Department of Materials Science and Engineering, Gachon University, Seongnam 13120, Korea \\ **Agency for Defense Development, Daejeon 34186, Korea
}

(Received March 15, 2019; Accepted April 21, 2019)

\begin{abstract}
Thermal batteries are reserve batteries with molten salts as an electrolyte, which activates at high temperature. Due to their excellent reliability, long shelf life, and mechanical robustness, thermal batteries are used in military applications. A high-performance cathode for thermal batteries should be considered in terms of its high capacity, high voltage, and high thermal stability. Research progress on cathode materials from the recent decade is reviewed in this article. The major directions of research were surface modification, compounding of existing materials, fabrication of thin film cathode, and development of new materials. In order to develop a high-performance cathode, a proper combination of these research directions is required while considering mass production and cost.
\end{abstract}

Key words : Thermal batteries, Cathode materials, High capacity, High voltage, High thermal stability

\section{Introduction}

$\mathrm{T}$ hermal batteries are reserve batteries that can be stored for a long period in an inactive state, which can then be activated to generate power when needed. Thermal batteries include molten salts as an electrolyte and employ an internal pyrotechnic source to bring the battery stack to the operating temperature. Thermal batteries are high-temperature power sources that typically operate between 350 and $550^{\circ} \mathrm{C}$. Thermal batteries are used for many military applications, such as power sources for guided missiles and proximity fuses in ordnance devices because of their excellent mechanical robustness, reliability, and long shelf life ${ }^{1)}$. The progress of research on thermal batteries until about 2006 is summarized in the review by Masset et al. ${ }^{1-5)}$ This review provides an overview of molten salt electrolytes, ${ }^{2)}$ cathode materials, ${ }^{3,4)}$ and molten salt electrolytes ${ }^{5)}$ of thermally activated batteries. As a representative thermal battery electrode, $\mathrm{Li}-\mathrm{Si}$ is used as an anode and $\mathrm{FeS}_{2}$ (pyrite) is used as a cathode; $\mathrm{LiCl}-\mathrm{KCl}$ is used as an electrolyte. Fig. 1 shows the basic structure of an $\mathrm{Li}-\mathrm{Si} / \mathrm{LiCl}-\mathrm{KCl} / \mathrm{FeS}_{2}$ thermal battery. So far, various studies have focused on optimizing each component in these systems. ${ }^{6-9)}$

Among them, studies focusing on the cathode are largely divided into materials and manufacturing methods. The most commonly used cathode material to date is $\mathrm{FeS}_{2}$. In addition to studies on optimizing electrode fabrication using

${ }^{\dagger}$ Corresponding author: Young Soo Yoon

E-mail : benedicto@gachon.ac.kr

Tel : +82-31-750-5596 Fax : +82-31-750-8839

ORCID

https://orcid.org/0000-0002-0214-9701
$\mathrm{FeS}_{2},{ }^{10-15)}$ studies have been conducted on the use of materials such as $\mathrm{CoS}_{2},{ }^{16-21)} \mathrm{NiS}_{2},{ }^{22-24)} \mathrm{NiCl}_{2},{ }^{25-28)} \mathrm{CuVO},{ }^{29-30)}$ and others. ${ }^{31-33)}$ Masset et al. cited the following key properties to be considered as cathode materials for thermal batteries: ${ }^{4)}$

- Redox potential: it should have a discharge potential that is compatible with the electrochemical window of the electrolyte in order to prevent oxidation.

- Ability to provide a fixed discharge plateau: it should undergo multiphase discharge and not intercalation.

- High thermal stability: thermal decomposition and associated possible chemical reactions caused by decomposition products should be minimized (e.g., $\mathrm{S}_{2}$ in the case of $\mathrm{FeS}_{2}$ reacting with the anode or pyrotechnic source in the battery).

- Electronically conductive: the resistance of the cathode should be minimized.

- Low solubility of the cathode materials in molten electrolytes: self-discharge reactions with attendant loss in capacity should be prevented.

- Low solubility of discharge products in the molten electrolytes: prevent self-discharge reactions.

- Stable towards moisture and/or oxygen: to prevent oxide production at the cathode surface.

- Ability to be wetted by electrolyte: this minimizes the contact resistance at the electrolyte (separator)/electrode interface.

- Good discharge kinetics (high exchange-current density): provides high rate capability.

- Reasonable costs.

- Being environmentally friendly is an additional desirable attribute.

The second area of focus in prior research is on the method for manufacturing the cathode electrode. Generally, 


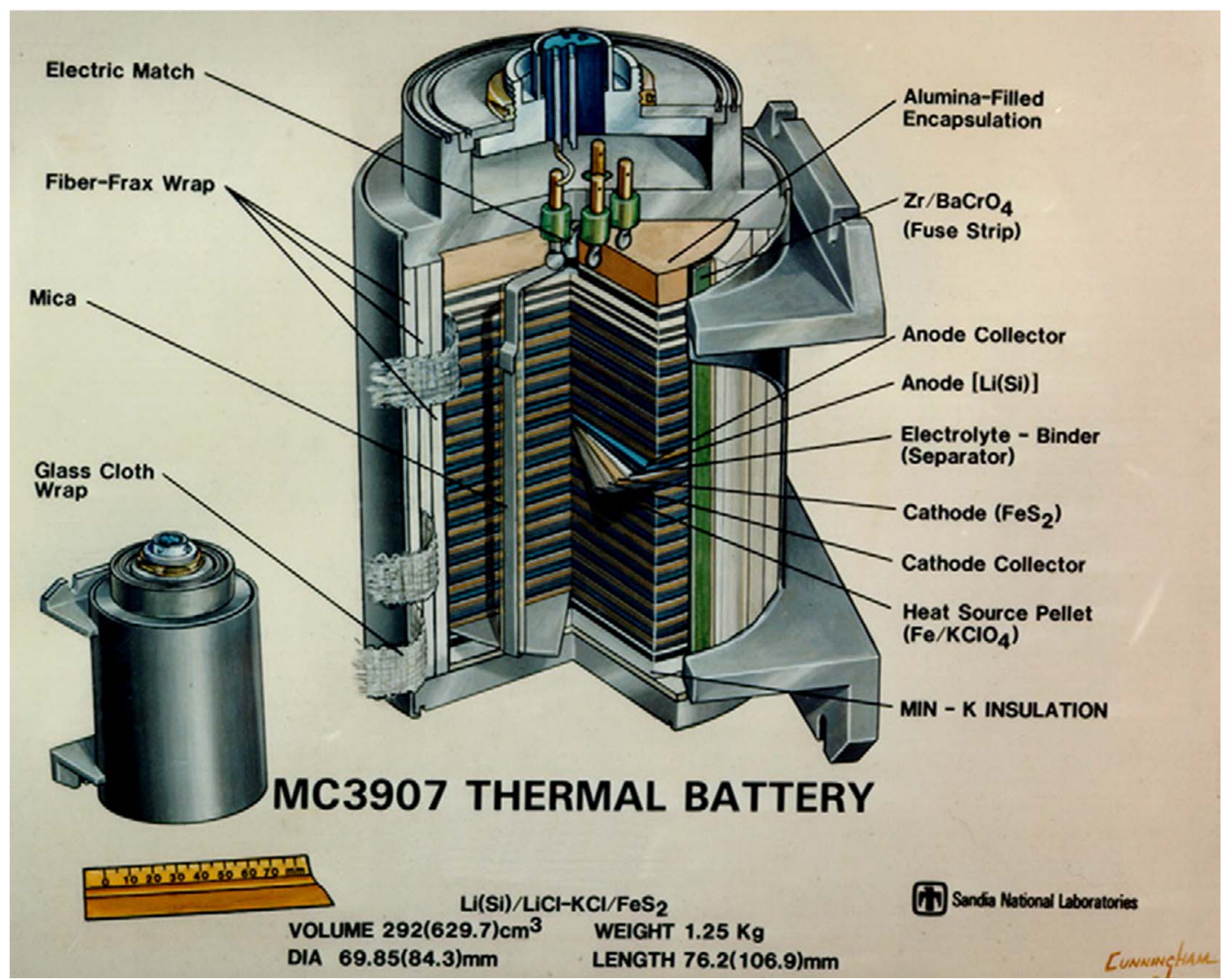

Fig. 1. Cross-sectional view of an $\mathrm{Li}-\mathrm{Si} / \mathrm{FeS}_{2}$ thermal battery. Reprinted with permission from Ref. [1]. Copyright 2006 Elsevier B. V.

the constituent materials are produced in the form of pellets with a thickness of several hundreds of micrometers using a powder compaction process. However, the formed pellets are thicker than the optimum thickness in terms of utilization of the electrode material because they must maintain a minimum mechanical strength. For these reasons, an electrolyte material is added to the electrode to compensate for the lower utilization of the electrode material. However, this approach makes the electrode becomes thicker and reduces the ratio of the active material in the electrode. When the thickness of the electrode pellet is greater than a certain level, electrode utilization decreases significantly, which may decrease the energy density of the thermal battery. To solve such a problem, it is essential to choose a process for thinning the electrode such that the electrode has sufficient mechanical strength with optimal electrochemical performance. Therefore, some studies focused on the use of a tape casting process to thin the cathode of a thermal battery. ${ }^{11-13)}$

In this review, the cathode materials of thermal batteries are reviewed in terms of material types and electrode manufacturing methods. The scope of this review is the past 10 years since the reviews published by Masset et al.. ${ }^{1-5)}$

\section{2. $\mathrm{FeS}_{2}$}

The intrinsic difficulties of engineering a thermal battery based on $\mathrm{Ca} / \mathrm{CaCrO}_{4}$ electrochemistry were obviated with the introduction of $\mathrm{Li}$-alloy/ $\mathrm{FeS}_{2}$ couples. ${ }^{1}{ }^{1}$ The performance of the $\mathrm{Ca} / \mathrm{CaCrO}_{4}$ electrochemical system tended to be somewhat unpredictable. ${ }^{1} \mathrm{FeS}_{2}$ was readily obtained from processing pyrite, which is a plentiful, inexpensive material compared to chemically synthesized $\mathrm{CaCrO}_{4}$. In addition, $\mathrm{FeS}_{2}$ has higher electrical conductivity at elevated temperatures. This provides improved power and lifetimes over the $\mathrm{Ca} / \mathrm{CaCrO}_{4}$ system. $^{3,4)}$ For these reasons, the Li-alloy/FeS $\mathrm{F}_{2}$ system is still the most widely used electrode for thermal batteries. However, the performance improvement is limited due to the low thermal stability and low open circuit voltage compared to other materials, and studies have been conducted to supplement these findings. ${ }^{10-15)}$

Lee et al. studied the use of carbon black and carbon nanotubes on an $\mathrm{FeS}_{2}$ cathode in $\mathrm{Li}-\mathrm{Si} / \mathrm{FeS}_{2}$ thermal batteries. ${ }^{10)}$ Discharge measurements and the calculated total polarization confirmed that the performance of the single cell improved when a carbonaceous material was added (Fig. 2(a, b)). In Fig. 2(c, d), Nyquist plots of data from the $\mathrm{FeS}_{2}$ cathode are shown for various contents of carbonaceous materials. The impedance of each sample increased as the content increased. The results from a pristine sample were not compared together; therefore, it is difficult to determine 
(a)

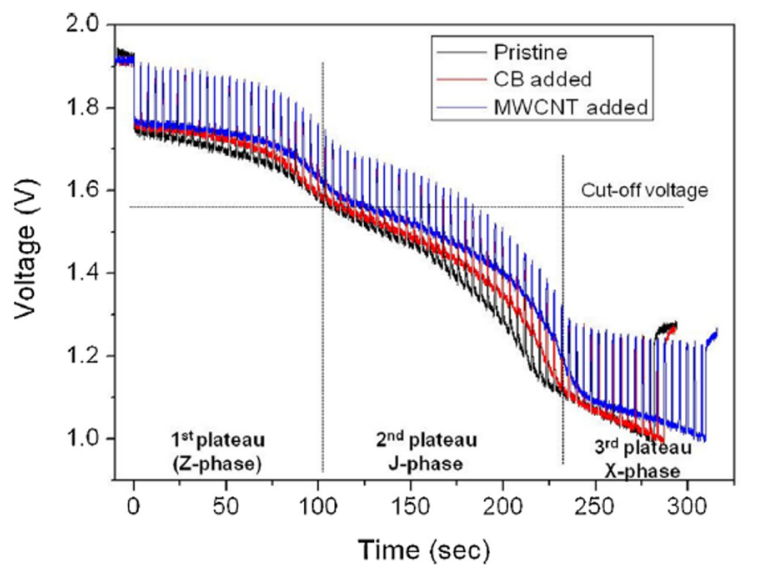

(c)

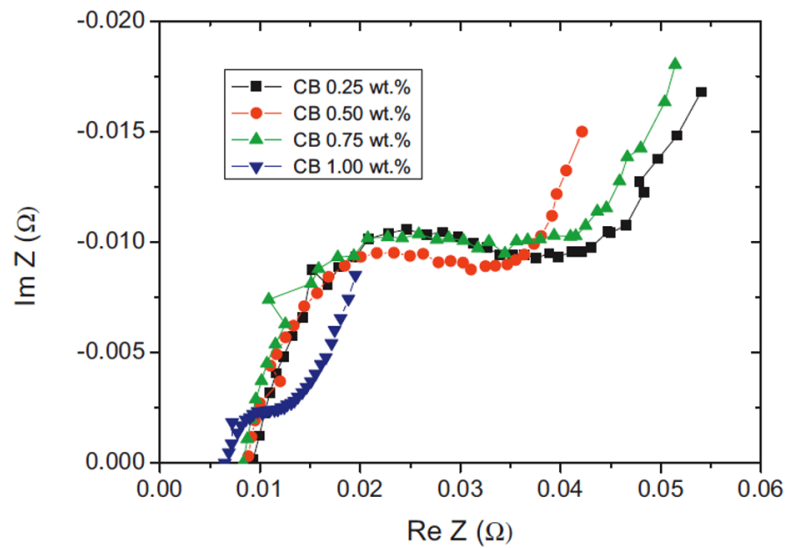

(b)

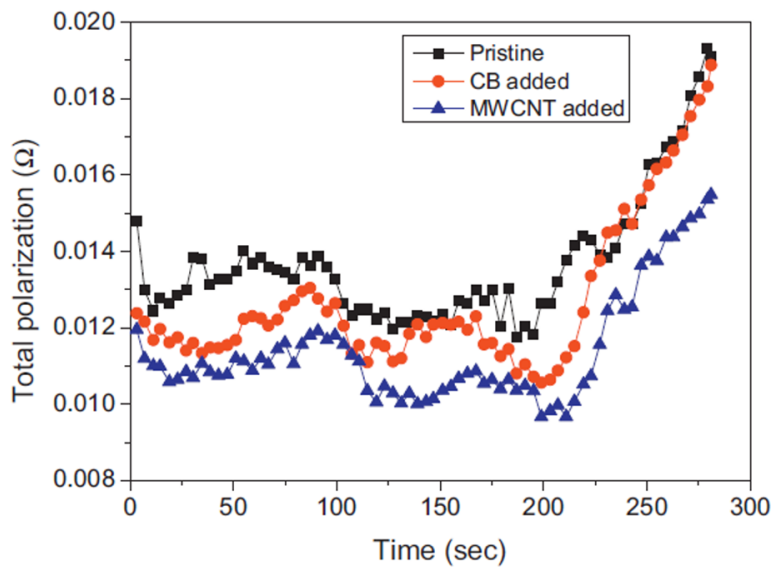

(d)

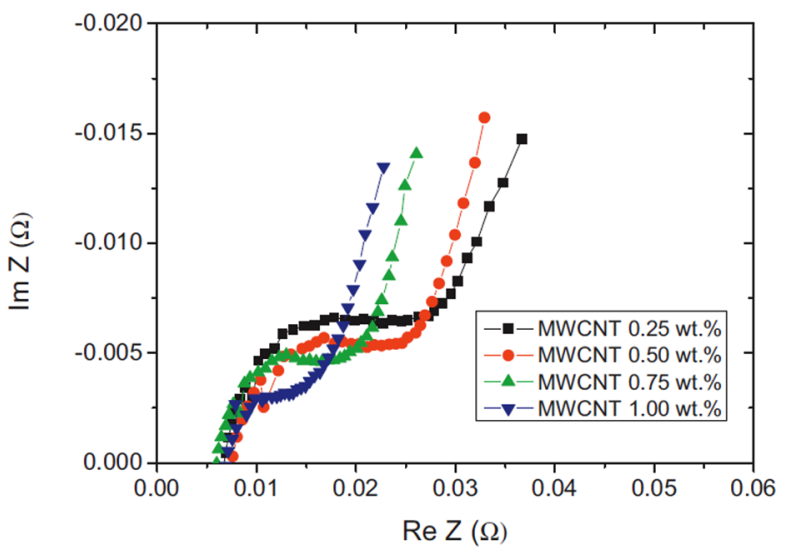

Fig. 2. (a) Single cell discharge results and (b) total polarization values of pristine, 0.1 wt.\% CB, and 0.1 wt.\% MWCNT samples. (c, d) Nyquist plots for CB-added and MWCNT-added samples. Reprinted with permission from Ref. [10]. Copyright 2013 The Korean Society of Industrial and Engineering Chemistry.

what level of impedance the $1 \mathrm{wt} \%$ sample represents. In addition, there is no information on how the impedance results were obtained when the content was more than 1 wt\%, as well as the discharge and total polarization results when the content was greater than $0.1 \mathrm{wt} \%$. Nevertheless, attempts were made to improve the performance of battery electrodes using carbonaceous materials, ${ }^{34-43)}$ and the effect was confirmed in the $\mathrm{FeS}_{2}$ cathode of thermal batteries. However, additional validation is required for actual mass production.

Yoon et al. fabricated and evaluated a thin cathode using a tape casting method instead of conventional pellet type cathode. ${ }^{11)}$ When producing a pellet with a powder compaction process, the thickness is minimized for mechanical strength, thus powder compaction is not an appropriate process from the perspective of optimizing the battery performance. In this study, tape casting was used to improve the utilization of cathode materials and the dispersion condition, binder type, and content of each material were determined. As shown in Fig. 3(a), a thin cathode with maximum content of $\mathrm{FeS}_{2}$ and a minimum amount of binder was pre- pared. Its mechanical strength was maintained even under severe deformation, as shown in Fig. 3(b), and its discharge rate was nearly twice that of the pellet type, as shown in the Fig. 3(c, d). Tape casting was used to overcome the limitation of a manufacturing process of an existing pellet and showed excellent performance.

Thin cathode production using tape casting was also studied from the perspective of the binder material. Jung et al. fabricated a high thermo-stable poly(imide-co-siloxane) (PIS) binder for thermal batteries and used it with an $\mathrm{FeS}_{2}$ thin cathode in tape casting. ${ }^{12)}$ The PIS binder is stable up to $400^{\circ} \mathrm{C}$ and decomposes at $450^{\circ} \mathrm{C}$ (Fig. 4(a)). Thus, it cannot be used at $500^{\circ} \mathrm{C}$, which is the operating temperature of normal thermal batteries, but shows a higher level compared to binder materials in typical secondary lithium batteries. ${ }^{44-48)}$ During discharge, $\mathrm{FeS}_{2}$ thin cathodes with PIS showed better performance than conventional pellet-type cathodes, and the total polarization was stable. The discharge capacity is lower than the results presented by Yoon et al.. ${ }^{11)}$ This may arise due to the difference in $\mathrm{FeS}_{2}$ particle size. The thermal battery is a special cell that operates at 
(a)

\begin{tabular}{llll}
\hline Thin cathode & \multicolumn{3}{c}{ Pellet type cathode } \\
\hline $\begin{array}{l}\mathrm{FeS}_{2} \\
\quad \text { (Active material) }\end{array}$ & $90 \mathrm{wt} \%$ & $\begin{array}{l}\mathrm{FeS}_{2} \\
\text { (Active material) }\end{array}$ & $75 \mathrm{wt} \%$ \\
$\begin{array}{c}\text { Silicic acid } \\
\text { (Binder) }\end{array}$ & $1.67 \mathrm{wt} \%$ & $\begin{array}{l}\mathrm{MgO} \\
\text { (Binder) }\end{array}$ & $8.75 \mathrm{wt} \%$ \\
$\begin{array}{c}\text { Polysiloxane } \\
\text { (Binder) }\end{array}$ & $8.33 \mathrm{wt} \%$ & $\begin{array}{l}\text { LiCl-KCl } \\
\text { (Electrolyte) }\end{array}$ & $16.25 \mathrm{wt} \%$ \\
\hline
\end{tabular}

(b)

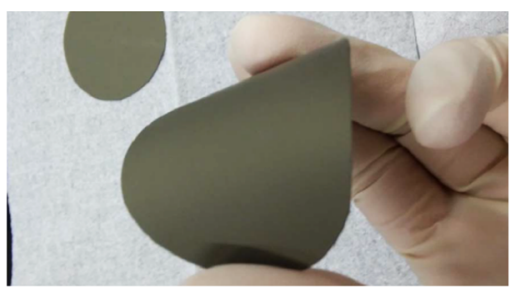

(c)

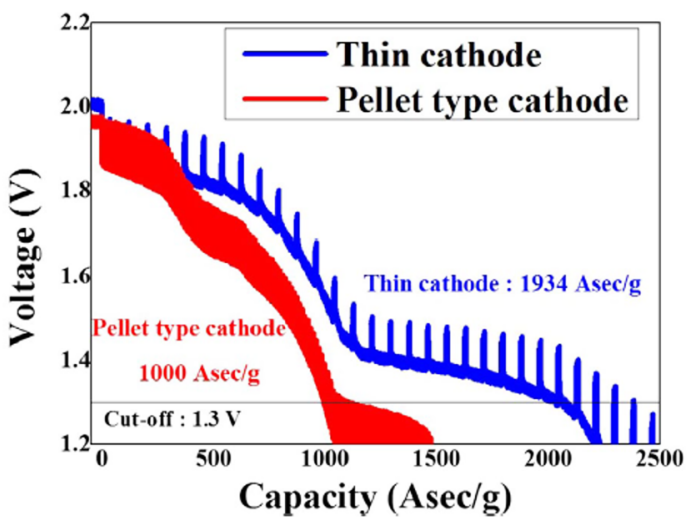

(d)

\begin{tabular}{lllll}
\hline Type & $\begin{array}{l}\text { Thickness } \\
(\mu \mathrm{m})\end{array}$ & $\begin{array}{l}\text { Weight } \\
(\mathrm{g})\end{array}$ & $\begin{array}{l}\text { Discharge time } \\
(\mathrm{s})\end{array}$ & $\begin{array}{l}\text { Discharge capacity } \\
(\mathrm{A} \mathrm{s} / \mathrm{g})\end{array}$ \\
\hline $\begin{array}{l}\text { Thin cathode } \\
\text { Pellet type cathode }\end{array}$ & 100 & 0.537 & 115.4 & 1934.08 \\
\hline
\end{tabular}

Fig. 3. (a) The contents of substances contained in the thin cathode and pellet type cathode. (b) Photograph of a thin cathode prepared using tape casting. (c) Discharge graphs of the thin cathode and pellet-type cathode. (d) Discharge results of the thin cathode and pellet-type cathode. Reprinted with permission from Ref. [11]. Copyright 2017 Elsevier Ltd and Techna Group S.r.l.

high temperature $\left(500^{\circ} \mathrm{C}\right)$, thus the active electrode material must have excellent thermal stability up to $500^{\circ} \mathrm{C}$. The thermal stability decreases when the particle size of $\mathrm{FeS}_{2}$ is reduced to a certain size or less, and the decomposition rate increases at $500^{\circ} \mathrm{C}$, which decreases the discharge capacity.

Another approach to the use of binder materials in thin cathode manufacturing using tape casting is to use multiwalled carbon nanotubes (MWCNTs). Yoon et al. applied MWCNTs, which have excellent mechanical strength and conductivity, as an alternative to conventional organic binders for the thin cathode of thermal batteries. ${ }^{13)}$ Carboneous materials have been extensively studied and used as additives for electrodes in rechargeable Li-ion batteries. ${ }^{34-43)}$ Among them, some carboneous materials are used as current collectors and as electrode supports without adding other binder materials. ${ }^{34,49-54)}$ Noda et al. showed that electrodes containing $99 \mathrm{wt} \%$ of active materials and $1 \mathrm{wt} \%$
CNTs can be produced. ${ }^{34)}$ However, more research is required to obtain stable cycle performance without electrode degradation in rechargeable batteries, where charge/discharge cycles repeat. On the other hand, thermal batteries are the primary batteries with only one discharge, and are more suitable than rechargeable batteries in active material-CNT composites as the electrode. That is, the use of an $\mathrm{FeS}_{2}$ MWCNT composite is a universal method in battery research, but is a suitable and novel method for manufacturing a thin cathode for a thermal battery. Two studies ${ }^{11,12)}$ related to thin cathode manufacturing with tape casting used organic binders and they were decomposed before reaching the operating temperature of $500^{\circ} \mathrm{C}$. The decomposed organic binder material can generate gas that aggravates the performance of the battery, and the residual material can act as a resistor. ${ }^{55-60)}$ To solve these problems, MWCNTs were used as a binder and conductor for the cathode electrode in this study. MWCNTs have better thermal stability than conventional organic binders and show a mass reduction rate of about $5 \%$ at $500^{\circ} \mathrm{C}$. Fig. 5(a) shows the contents of each type of cathode. The $\mathrm{FeS}_{2}$-MWCNT composite cathode has a higher content of $\mathrm{FeS}_{2}$ than the other types. This is an important factor for increasing the energy density. As shown in Fig. 5(b, c), the $\mathrm{FeS}_{2}$-MWCNTs composite cathode exhibits higher capacity than the cathode with an organic binder of the same thickness. In this study, MWCNTs are added as a binder in a small amount compared to an organic binder and act as a conductor.

All three of the aforementioned studies ${ }^{11-13)}$ focus on thin cathode manufacturing methods using tape casting. These are new attempts in terms of manufacturing methods to maximize the performance of thermal batteries based on the material properties of $\mathrm{FeS}_{2}$. That is, it is meaningful to maximize the utilization ratio of the electrode material, which is poor in the production of the conventional pellettype material, by manufacturing the electrode with the optimum thickness form an electrochemical perspective. Thin cathode manufacturing is possible with tape casting or with any other method capable of producing films with an appropriate thickness, such as spraying ${ }^{61-65)}$ or screen-printing. ${ }^{66-70)}$ Rather, the key to thin cathode manufacturing is high performance, stable, highly productive slurry manufacturing technology. ${ }^{71-74)}$ Of course, thin cathode manufacturing technology is applicable not only to $\mathrm{FeS}_{2}$ but also to other cathode materials. For this purpose, it is necessary to study the binder, solvent, and dispersant suitable for each cathode material.

\section{3. $\mathrm{CoS}_{2}$ and Bimetallic (Fe-Co) Disulfides}

$\mathrm{CoS}_{2}$ has a lower solubility in molten electrolytes and much higher electronic conductivity, which permits a higher discharge rate. Most importantly, it has a much higher thermal stability and decomposes only above $650^{\circ} \mathrm{C}$, which is $\sim 100^{\circ} \mathrm{C}$ higher than for $\mathrm{FeS}_{2}$, facilitating its long-term application. However, the major disadvantage of $\mathrm{CoS}_{2}$ rela- 
(a)

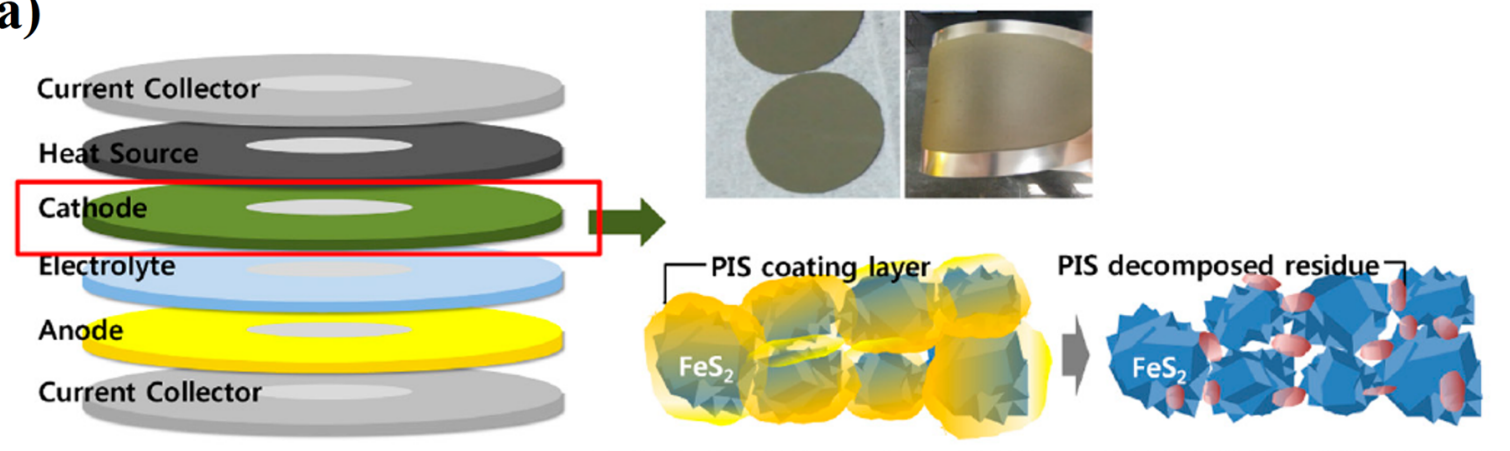

Conservation period at r.t. $400^{\circ} \mathrm{C} \quad$ Working temperature at $450^{\circ} \mathrm{C}$

(b)

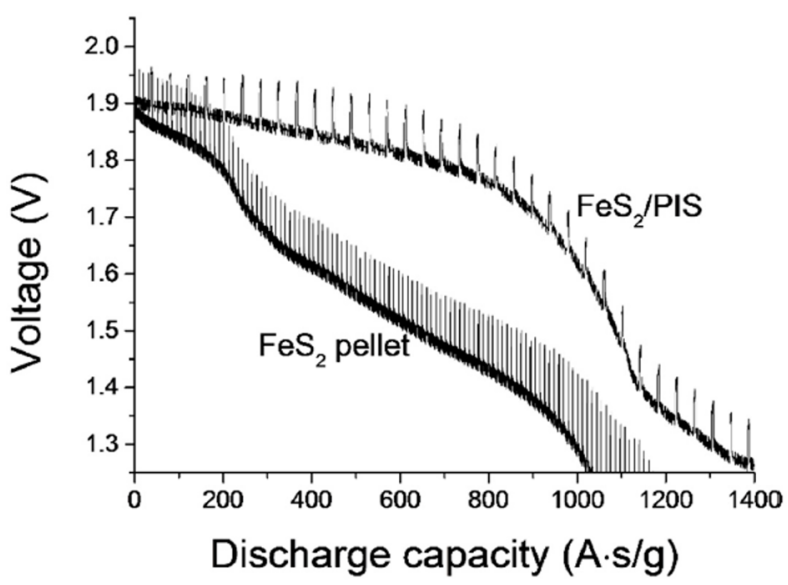

(d)

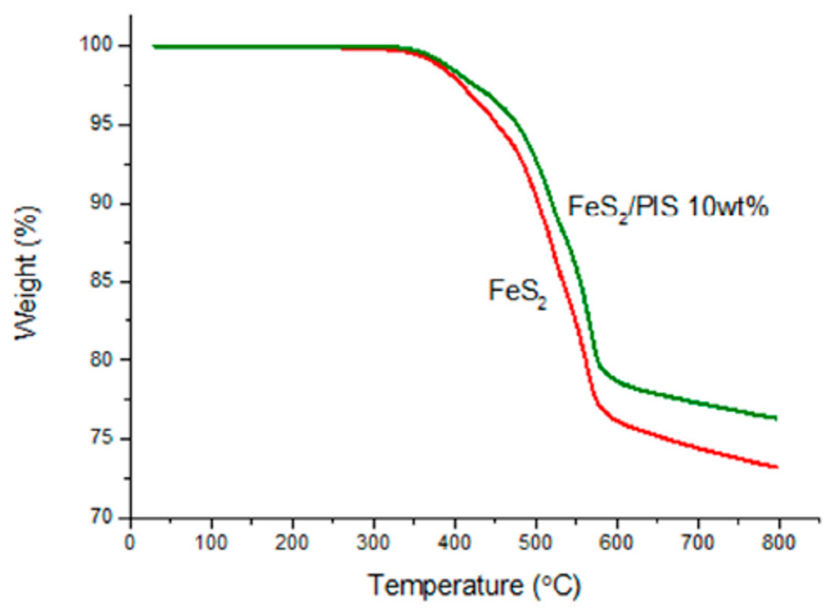

(c)
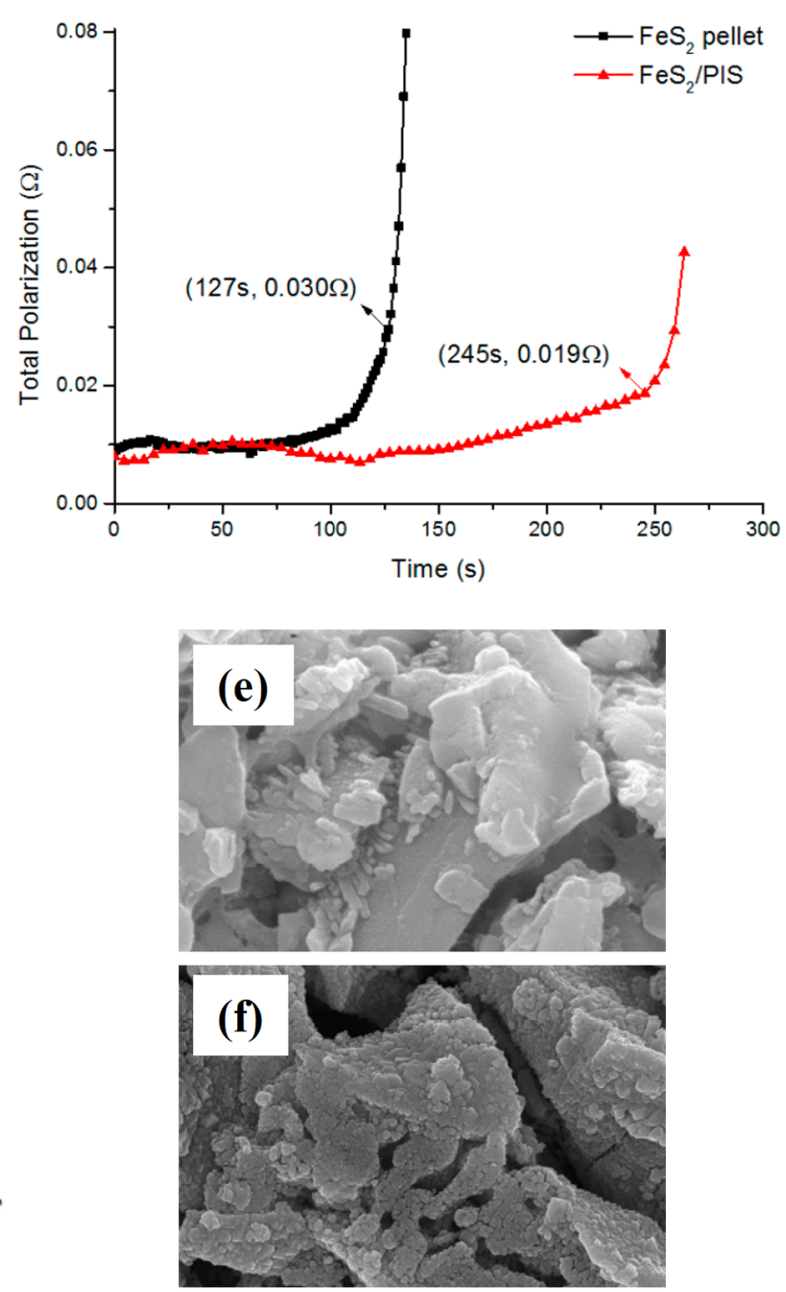

Fig. 4. (a) Schematic view of the $\mathrm{FeS}_{2}$ /poly(imide-co-siloxane) composite cathode. (b, c) Discharge capacity and total polarization of the $\mathrm{FeS}_{2} / \mathrm{PIS}$ thin cathode and pellet type cathode. (d) TGA data. (e, f) SEM images of the thin cathode and pellet-type cathode after $1 \mathrm{~h}$ treatment at $450^{\circ} \mathrm{C}$. Reprinted with permission from Ref. [12]. Copyright: This is an open access article distributed under the Creative Commons Attribution License.

tive to $\mathrm{FeS}_{2}$ is its higher cost. ${ }^{4)}$ Nevertheless, $\mathrm{CoS}_{2}$ generally has better properties than $\mathrm{FeS}_{2}$. For this reason, studies on thermal batteries using $\mathrm{CoS}_{2}$ cathodes have continued until recently.
Zhu et al. fabricated $\mathrm{CoS}_{2}$ thin cathodes using a screenprinting method and confirmed its feasibility. ${ }^{16)}$ This study was conducted in the same context as the aforementioned $\mathrm{FeS}_{2}$ cathode fabricated as a thin film type using tape cast- 


\begin{tabular}{|c|c|c|c|c|c|}
\hline \multicolumn{2}{|c|}{$\begin{array}{c}\text { Thin cathode } \\
\left(\text { FeS }_{2} \text {-MWCNTs composite) }\right.\end{array}$} & \multicolumn{2}{c|}{$\begin{array}{c}\text { Thin cathode } \\
\text { (Organic binder) }\end{array}$} & \multicolumn{2}{c|}{ Pellet type cathode } \\
\hline $\mathrm{FeS}_{2}$ & $98 \mathrm{wt} \%$ & $\mathrm{FeS}_{2}$ & $90 \mathrm{wt} \%$ & $\mathrm{FeS}_{2}$ & $75 \mathrm{wt} \%$ \\
\hline MWCNTs & $2 \mathrm{wt} \%$ & $\begin{array}{c}\text { Silicic acid } \\
\text { (Binder) }\end{array}$ & $1.67 \mathrm{wt} \%$ & $\begin{array}{c}\mathrm{MgO} \\
\text { (Binder) }\end{array}$ & $8.75 \mathrm{wt} \%$ \\
\hline- & - & $\begin{array}{c}\text { Polysiloxane } \\
\text { (Binder) }\end{array}$ & $8.33 \mathrm{wt} \%$ & $\begin{array}{c}\text { LiCl-KCl } \\
\text { (Electrolyte) }\end{array}$ & $16.25 \mathrm{wt} \%$ \\
\hline
\end{tabular}

(b)

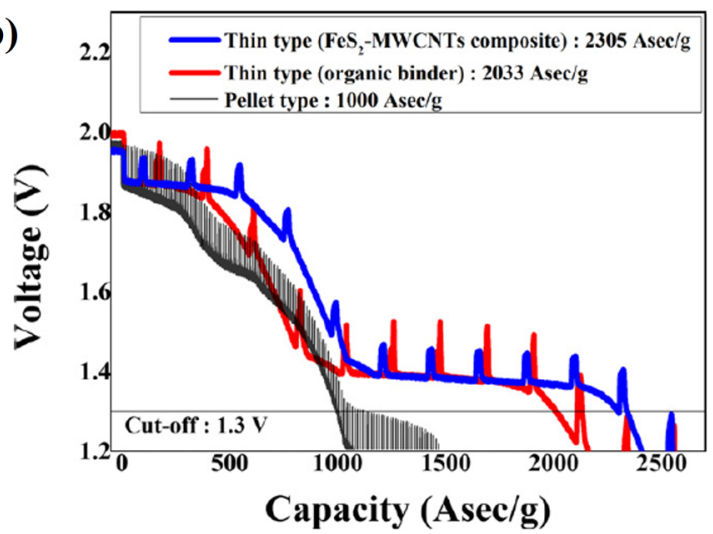

(c)

\begin{tabular}{|c|c|c|c|c|}
\hline Type & $\begin{array}{l}\text { Weight } \\
\text { (g) }\end{array}$ & $\begin{array}{l}\text { Thickness } \\
(\mu \mathrm{m})\end{array}$ & $\begin{array}{l}\text { Discharge } \\
\text { time (s) }\end{array}$ & $\begin{array}{l}\text { Discharge } \\
\text { capacity } \\
\text { (Asec/g) }\end{array}$ \\
\hline $\begin{array}{l}\text { Thin cathode } \\
\text { (FeS }{ }_{2} \text {-MWCNTs } \\
\text { composite) }\end{array}$ & 0.203 & 50 & 52 & 2305.42 \\
\hline $\begin{array}{l}\text { Thin cathode } \\
\text { (Organic } \\
\text { binder) }\end{array}$ & 0.208 & 50 & 47 & 2033.65 \\
\hline Pellet type cathode & 3.6 & 500 & 400.1 & 1000.25 \\
\hline
\end{tabular}

Fig. 5. (a) Content of substances contained in the cathodes. (b) Discharge graphs of the cathodes. (c) Discharge results of the cathodes. Reprinted with permission from Ref. [13]. Copyright 2017 The American Ceramic Society.

ing. ${ }^{11-13)}$ That is, a method for optimizing the thickness in order to maximize utilization of the electrode material was used. $\mathrm{A} \mathrm{CoS}_{2}$ cathode material and screen-printing method were used. Screen-printing is widely used in the textile and electronics industries, and it is a remarkably simple and reproducible production method. In other words, applying this method to thin cathode fabrication for thermal batteries is an appropriate choice. However, this study seems to have a problem in selecting the binder material. In this study, PVDF, which is widely used in the production of electrodes for lithium ion batteries, is used to prepare slurries for screen-printing. However, because the melting point of PVDF is about $160^{\circ} \mathrm{C}$, it is not suitable for use in thermal batteries with operating temperatures of approximately 400 to $500^{\circ} \mathrm{C}$. As shown in Fig. 6(a), a thin cathode was fabricated with a thickness of $50 \mathrm{\mu m}$. As shown in Fig. 6(b), the discharge capacity was more than double that of the pellettype cathode, producing high voltage and low resistance. However, as described in the aforementioned studies using tape casting, ${ }^{11-13)}$ it is a natural phenomenon that the utilization rate of the electrode increases to a certain point and the discharge capacity increases when the electrode is thin. In the case of the pellet-type electrode, the thickness of about $500 \mu \mathrm{m}$ due to the limited mechanical strength, and lost electrode utilization is minimized by adding an electrolyte material. The key points of research for fabricating a thin cathode are 1) material selection (e.g., active material, binder, solvent, and dispersant) and 2) manufacturing method (e.g., tape casting, screen-printing, or spraying). With respect to these two issues, processing methods such as tape casting, ${ }^{75,76)}$ screen-printing, ${ }^{77-82)}$ and spraying ${ }^{83-89)}$ have already been sufficiently investigated in other fields. Of course, appropriate equipment modifications are necessary depending on the application, but this is considered less important than material selection. Very high reliability is required because the thermal battery is a special battery that is primarily used for military applications. Therefore, additional studies on material selection are required to demonstrate the performance while being suitable for the application environment.

Liu et al. showed that $\mathrm{CoS}_{2} / \mathrm{CNTs}$ composites were prepared using a facile, simple hydrothermal growth process for $\mathrm{CoS}_{2}$ in the presence of CNTs, as a novel approach of synthesizing cathode composites for thermal battery fabrication. ${ }^{17)}$ The incorporation of CNTs in the synthesized $\mathrm{CoS}_{2}$ cathode materials effectively improved the electrical conductivity and discharge performance of the resulting cathode. In this study, single cells with a $\mathrm{CoS}_{2} / \mathrm{CNT}_{\text {s }}$ cathode, an $\mathrm{LiCl}-\mathrm{KCl}$ electrolyte, and an $\mathrm{Li}-\mathrm{Si}$ anode were fabricated and evaluated. All components were fabricated into pellettype materials using a powder compaction process. This study addresses the addition of CNTs to improve the electrochemical properties of pellet-type cathodes, as in the work of Lee et al.. ${ }^{10)}$ The difference between them is the type of active material and the method used to add CNTs. In this study, $\mathrm{CoS}_{2}$ was used as a cathode material and a $\mathrm{CoS}_{2} / \mathrm{CNT}$ composite was fabricated using a hydrothermal method. Hydrothermal growth was carried out at $180^{\circ} \mathrm{C}$ by adding CNTs and $\mathrm{CoS}_{2}$ raw materials to a CNT dispersion. There is no mention of the advantages of hydrothermal reacting raw materials and electrical additive over conventional mixing methods. Intuitively, when the hydrothermal method is used, the interfacial properties of $\mathrm{CoS}_{2}$ and CNTs improve and the electrical conductivity and discharge performance of the cathode are expected to increase. ${ }^{90-92)}$ However, in this study, the content is not shown, and the goal is to compare $\mathrm{CoS}_{2} / \mathrm{CNT}$ s with $\mathrm{CoS}_{2}$. Fig. 7(a) shows that the thermal stability of $\mathrm{CoS}_{2} / \mathrm{CNTs}$ and $\mathrm{CoS}_{2}$ are similar. The low thermal stability of $\mathrm{CoS}_{2} / \mathrm{CNTs}$ is due to the addition of small amounts of CNTs. $\mathrm{CoS}_{2} / \mathrm{CNTs}$ with thermal stability above $600^{\circ} \mathrm{C}$ can perform better than $\mathrm{FeS}_{2}$ or $\mathrm{FeS}_{2}$ /additive composites. The discharge evaluation results show that the $\mathrm{CoS}_{2} / \mathrm{CNT}$ cathode exhibited excellent performance in all aspects, such as discharge capacity and resistance. However, as in the case of $\mathrm{FeS}_{2}$, additional validation experi- 
(a)

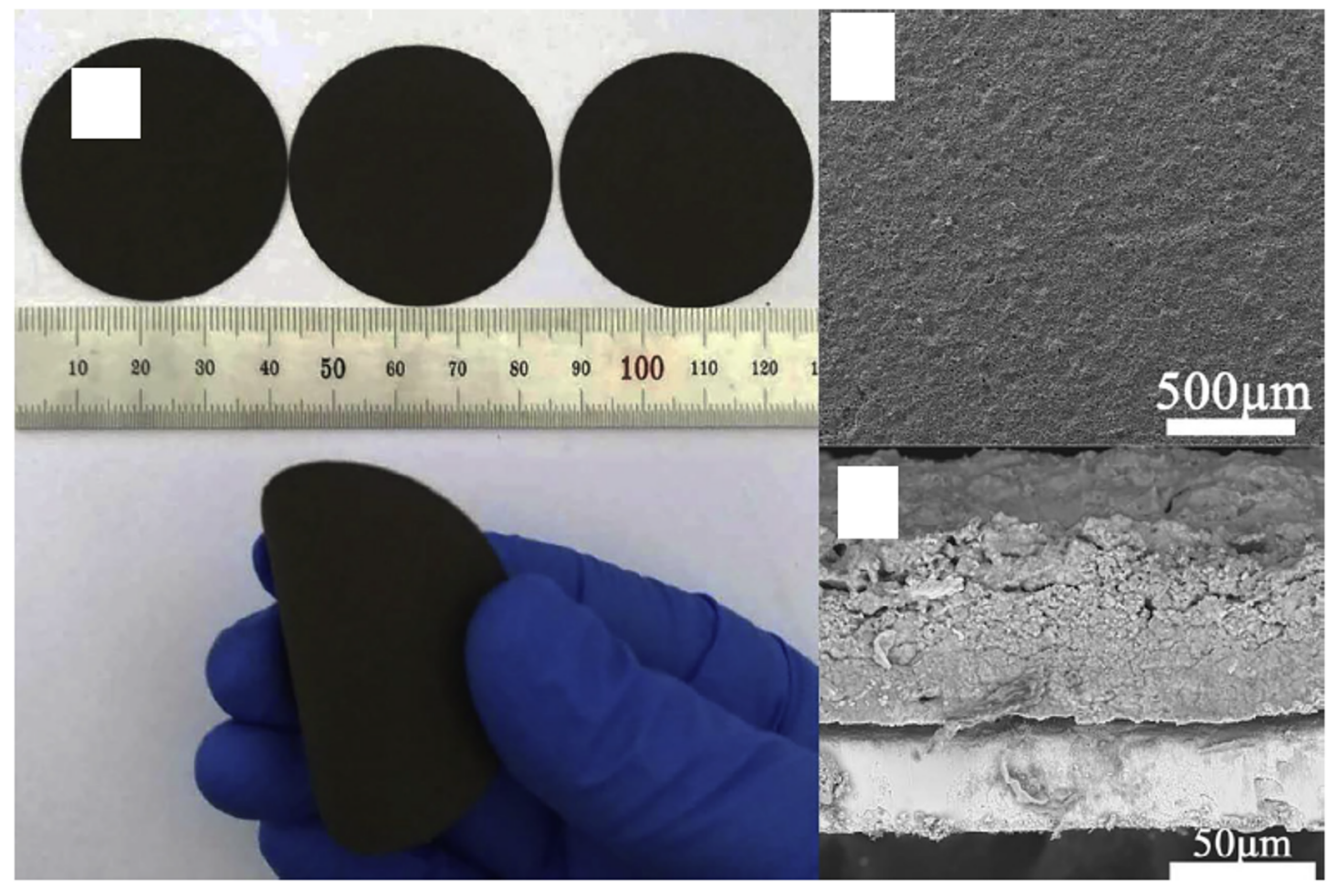

(b)
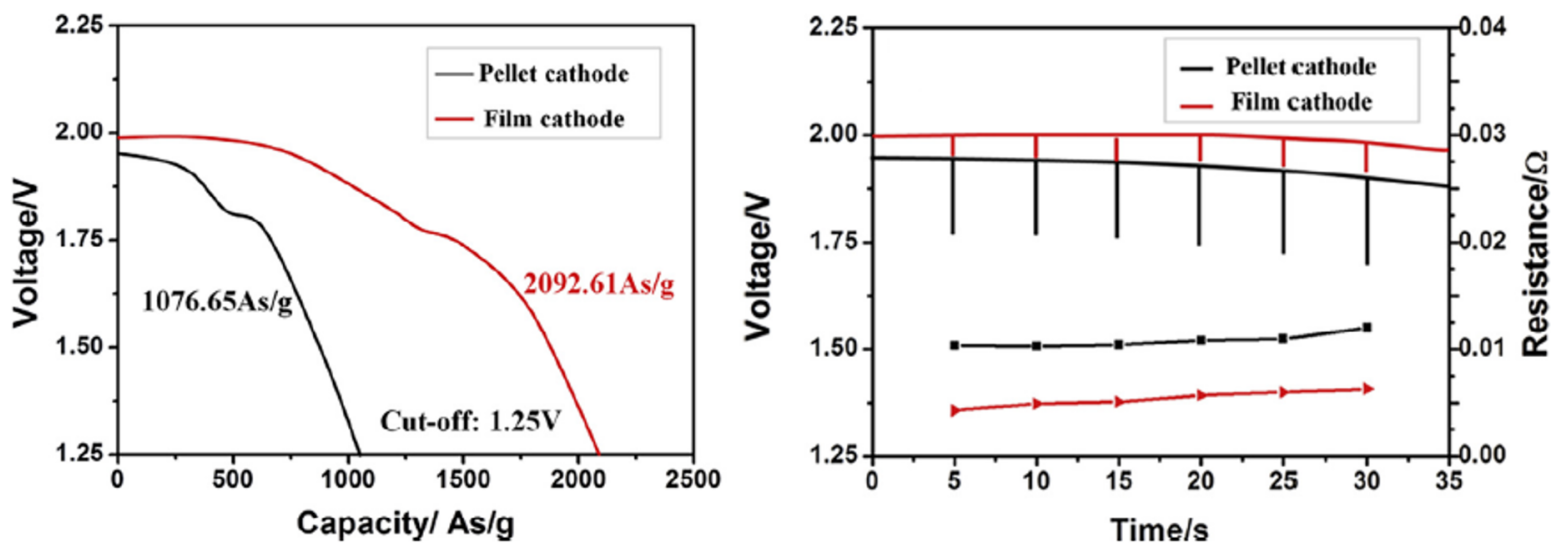

Fig. 6. (a) Photograph and SEM images of a thin film cathode prepared using screen-printing. (b) Discharge curves and (c) resistance changes of the thin cathode and pellet cathode. Reprinted with permission from Ref. [16]. Copyright 2017 Elsevier B. V.

ments are required based on these results.

Liu et al. also studied carbon-coated $\mathrm{CoS}_{2}$ that was fabricated using hydrothermal synthesis. ${ }^{18)}$ In this work, a carbon-coated $\mathrm{CoS}_{2}$ composite was prepared using a facile onepot hydrothermal method with glucose as a carbon source. During the growth of $\mathrm{CoS}_{2}$, the glucose molecules were adsorbed and carbonized in situ on the surface of the as-synthesized $\mathrm{CoS}_{2}$, and the resulting carbon coating provided improved electrical conductivity and discharge performance to the composite. In addition to improving the electrochemical performance, the carbon coating also improves the stability of $\mathrm{CoS}_{2}$ in air. In this study, single cells composed of a carbon-coated $\mathrm{CoS}_{2}$ cathode, an $\mathrm{LiCl}-\mathrm{KCl}$ electrolyte, and an $\mathrm{Li}-\mathrm{Si}$ anode were fabricated and evaluated. All components were fabricated into pellet-type materials using a powder compaction process. The stability of the carbon-coated $\mathrm{CoS}_{2}$ and bare $\mathrm{CoS}_{2}$ in air is shown in the XRD and TGA data in Fig. 8(a, b). After 3 months, impure peaks were detected in bare $\mathrm{CoS}_{2}$, while the carbon-coated $\mathrm{CoS}_{2}$ remained pure. In addition, bare $\mathrm{CoS}_{2}$ decomposition occurred before $400^{\circ} \mathrm{C}$ after 3 months, while the carbon-coated $\mathrm{CoS}_{2}$ remained relatively stable. In the discharge evaluation results, the carbon-coated $\mathrm{CoS}_{2}$ cathode showed excellent performance compared to bare $\mathrm{CoS}_{2}$ in all aspects, such as discharge capacity and resistance. However, as in the case of $\mathrm{CoS}_{2} /$ CNT composites, additional verification tests are required before beginning mass production.

Yu et al. used other approaches to improve the stability of $\mathrm{CoS}_{2}$ in air. In this work, Fe-doped $\mathrm{CoS}_{2}\left(\mathrm{Co}_{\mathrm{X}} \mathrm{Fe}_{1-\mathrm{X}} \mathrm{S}_{2}\right)$ compounds were synthesized and evaluated as cathode materi- 

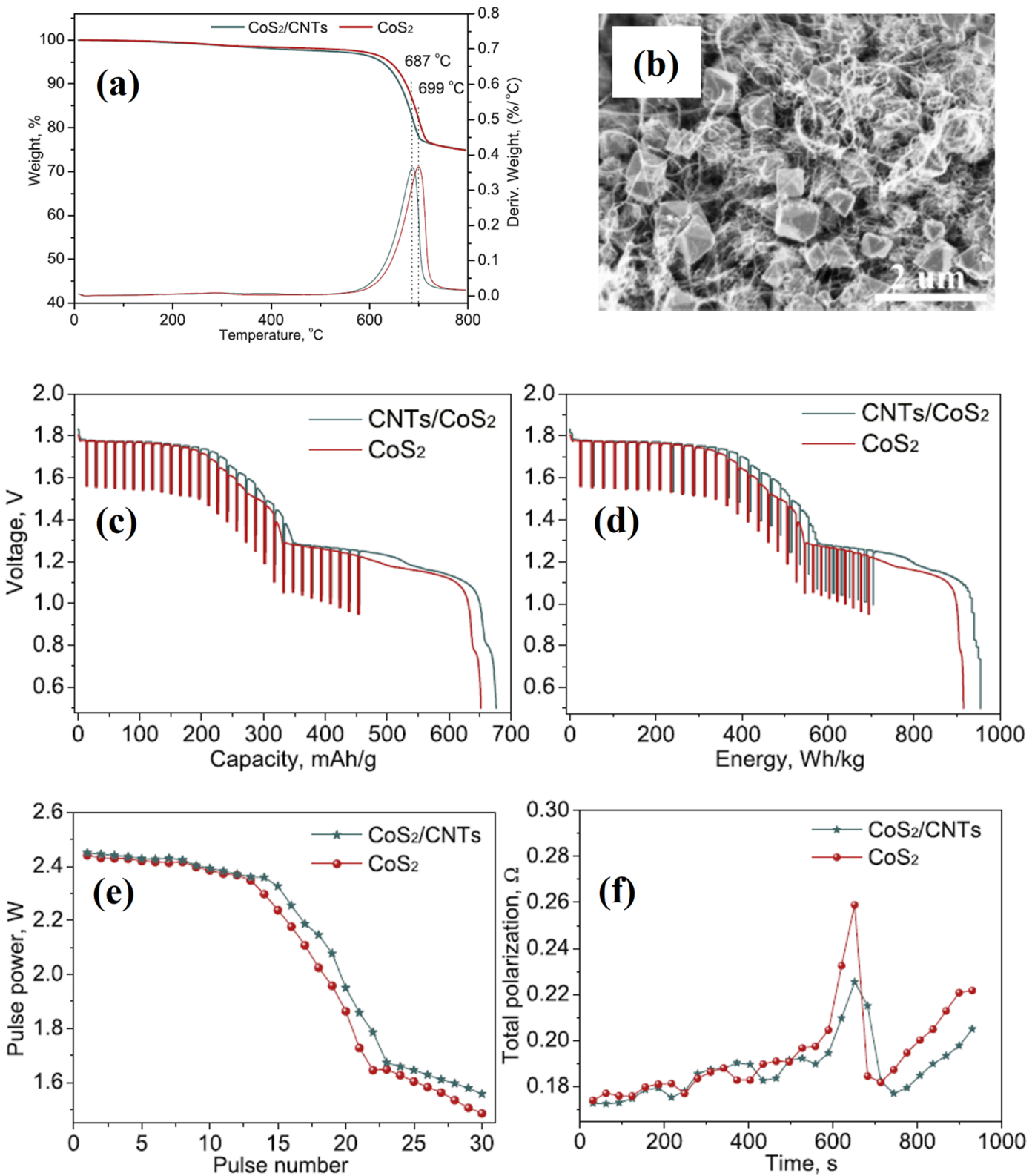

Fig. 7. (a) Thermal stability of $\mathrm{CoS}_{2}$ and $\mathrm{CoS}_{2} / \mathrm{CNTs}$. (b) SEM image of $\mathrm{CoS}_{2} / \mathrm{CNTs}$. (c) Specific discharge capacity, (d) energy, (e) pulse power, and (f) polarization data from $\mathrm{CoS}_{2}$ and $\mathrm{CoS}_{2} / \mathrm{CNT}$. Reprinted with permission from Ref. [17]. Copyright 2016 Elsevier Ltd.

als for thermal batteries. ${ }^{19)}$ Single cells composed of a $\mathrm{Co}_{\mathrm{X}} \mathrm{Fe}_{1-\mathrm{X}} \mathrm{S}_{2}$ cathode, an $\mathrm{LiCl}-\mathrm{KCl}$ electrolyte, and an $\mathrm{Li}-\mathrm{Si}$ anode were fabricated and evaluated. All components were fabricated into pellet-type materials using a powder compaction process. To investigate the stability of $\mathrm{Co}_{\mathrm{X}} \mathrm{Fe}_{1-\mathrm{x}} \mathrm{S}_{2}$ in air the as-prepared samples were stored in air $\left(25^{\circ} \mathrm{C}, 100 \%\right.$ relative humidity) for 7 days. The XRD patterns Fig. 9(a) do not reveal any apparent impurities or secondary phases in the $\mathrm{S}-\mathrm{FeS}_{2}$ sample, illustrating the stability of $\mathrm{FeS}_{2}$ in air. Obvious diffraction peaks corresponding to $\mathrm{CoSO}_{4} \cdot \mathrm{H}_{2} \mathrm{O}$ can be seen as the content of Co increased further, especially for the $\mathrm{S}-\mathrm{CoS}_{2}$. These results reveal that bimetallic disulfide has better stability in air than that of $\mathrm{CoS}_{2}$. As shown in
Fig. 9(b, c), the bimetallic disulfide sample was superior to $\mathrm{CoS}_{2}$ in terms of its electrochemical performance, such as its discharge capacity and total polarization. As shown in Fig. $7(\mathrm{~d})$, the discharge capacities of $\mathrm{S}-\mathrm{CoS}_{2}$ and $\mathrm{S}^{-\mathrm{Co}_{0.7}} \mathrm{Fe}_{0.3} \mathrm{~S}_{2}$ distinctly decrease due to formation of a large amount of $\mathrm{CoSO}_{4} \cdot \mathrm{H}_{2} \mathrm{O}$, while the $\mathrm{S}-\mathrm{Co}_{0.3} \mathrm{Fe}_{0.7} \mathrm{~S}_{2}$ still exhibits good discharge capacity. These results indicate that stability in air has a significant impact on the discharge performance of the disulfides. Bimetallic disulfides with suitable Fe content can exhibit stable discharge performance in air.

This approach was also studied by Zhu et al.. ${ }^{20)}$ This study shows that composite sulfide $\mathrm{Fe}_{0.5} \mathrm{Co}_{0.5} \mathrm{~S}_{2}$ can be prepared through traditional high-temperature solid-state and liquid 

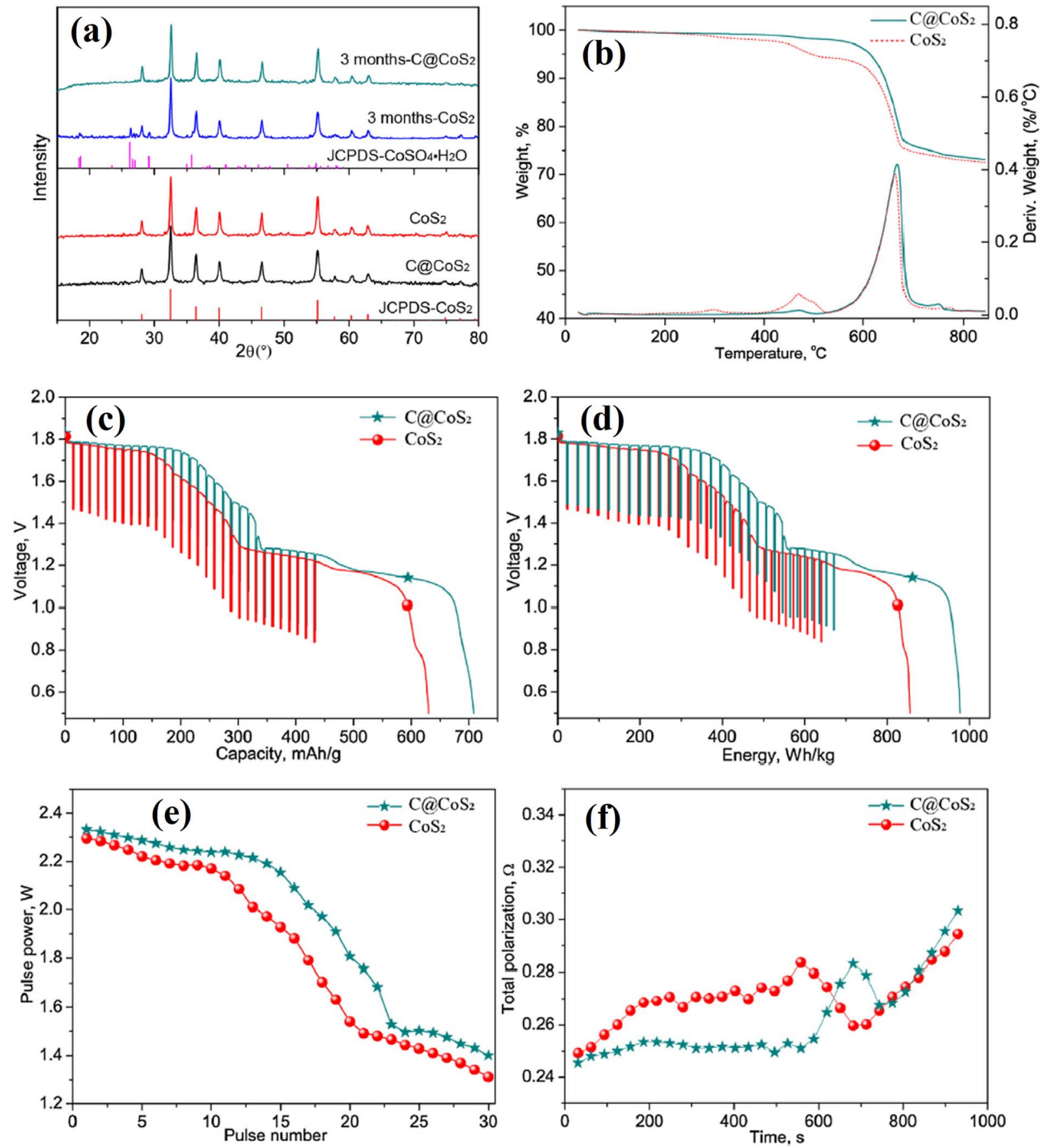

Fig. 8. (a) XRD patterns of fresh products and products that were stored for 3 months. (b) TG curves of $\mathrm{CoS}_{2}$ and $\mathrm{C} @ \mathrm{CoS}_{2}$ after being stored in dry air for 3 months. (c) Discharge capacity, (d) energy, (e) pulse power, and (f) polarization data from $\mathrm{CoS}_{2}$ and C@CoS . Reprinted with permission from Ref. [18]. Copyright 2017 published by Elsevier Ltd.

phase methods, and this composite can be used as a cathode material in thermal batteries. ${ }^{20)}$ The goal of this study is to improve the poor thermal stability of $\mathrm{FeS}_{2}$ and the poor stability of $\mathrm{CoS}_{2}$ in air by applying Fe-Co bimetallic disulfide. In this study, single cells composed of a $\mathrm{Fe}_{0.5} \mathrm{Co}_{0.5} \mathrm{~S}_{2}$ cathode, an LiCl-LiBr-LiF electrolyte, and an Li-Si anode were fabricated and evaluated. The cathode was made of thin film using screen-printing, and other components were fabricated into a pellet-type material using a powder compaction process. PVDF was used as a binder in thin-cathode manufacturing using screen-printing, as in the work of Zhu et $a l . .{ }^{16)}$ In order to manufacture a thin cathode with high reliability, the application of a heat-resistant binder should be considered. Clearly, one can see in Fig. 10(a) that a liquidphase-synthesized $\mathrm{Fe}_{0.5} \mathrm{Co}_{0.5} \mathrm{~S}_{2}$ sample is purely single-phase while still maintaining a pyrite structure. All diffraction peaks shifted to lower angles than those observed from cubic $\mathrm{FeS}_{2}$. As shown in Fig. 10 (b), $\mathrm{Fe}_{0.5} \mathrm{Co}_{0.5} \mathrm{~S}_{2}$ has better 

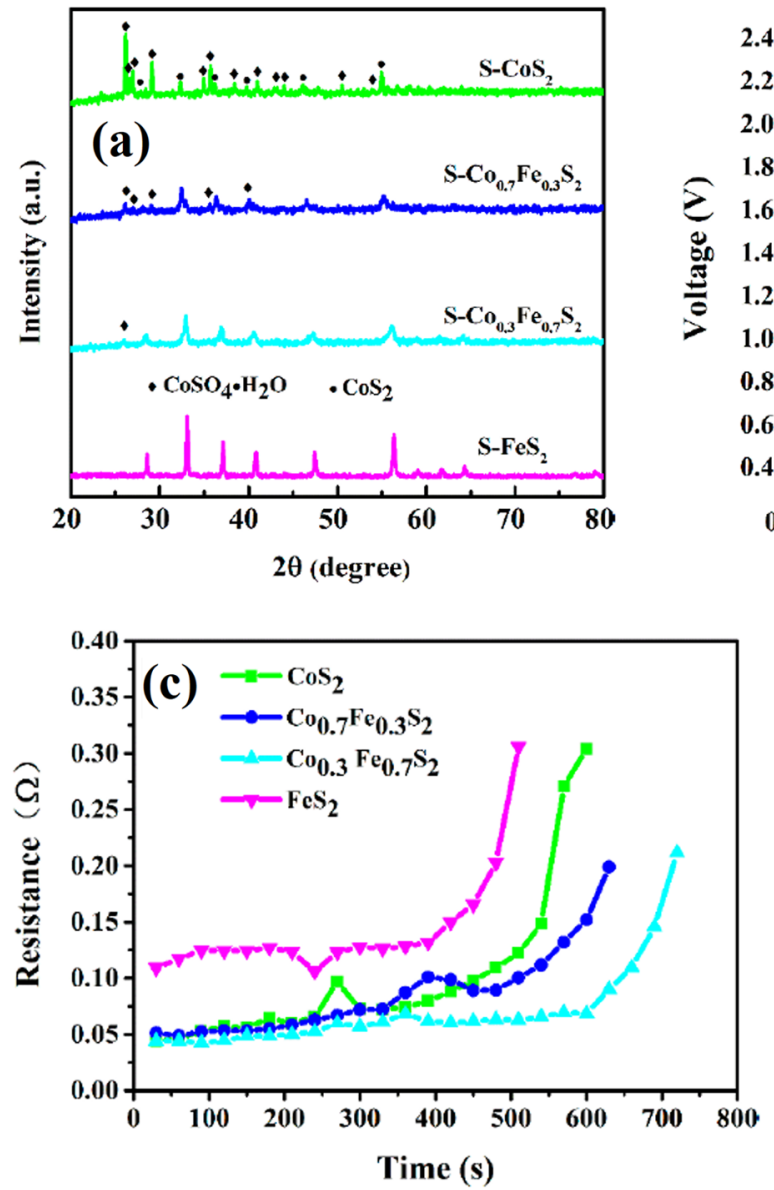
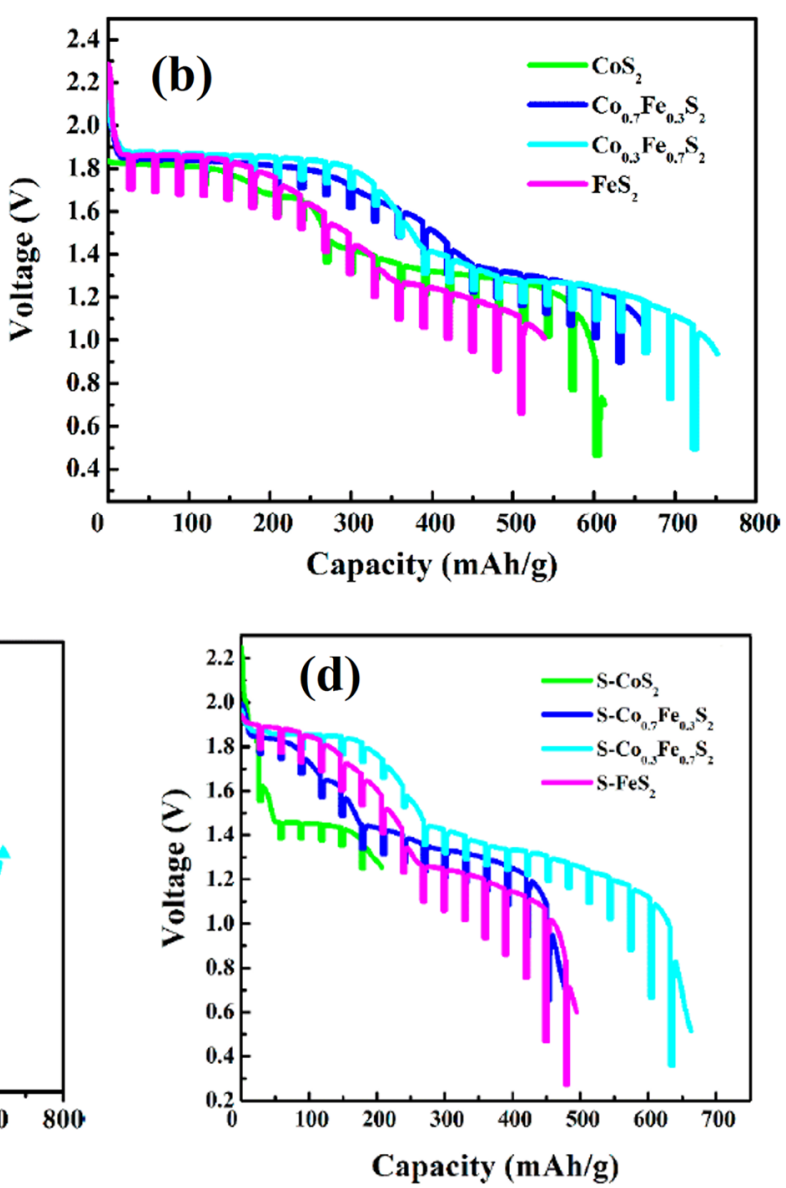

Fig. 9. (a) XRD patterns of $\mathrm{S}-\mathrm{Co}_{X} \mathrm{Fe}_{1-\mathrm{X}} \mathrm{S}_{2}$ (samples stored in air). (b) Discharge performance and (c) resistance of the $\mathrm{Co}_{\mathrm{X}} \mathrm{Fe}_{1-\mathrm{X}} \mathrm{S}_{2}$ cell. (d) Discharge performance of the $\mathrm{S}-\mathrm{Co}_{\mathrm{X}} \mathrm{Fe}_{1-\mathrm{X}} \mathrm{S}_{2}$ cell. Reprinted with permission from Ref. [19]. Copyright: This is an open access article distributed under the Creative Commons Attribution License.

thermal stability compared to $\mathrm{FeS}_{2}$. Better thermal stability points to a higher utilization rate for electrode materials, which can greatly increase the discharge performance. Fig. 10(c, d) shows the morphology of $\mathrm{Fe}_{0.5} \mathrm{Co}_{0.5} \mathrm{~S}_{2}$ prepared using solid-state and liquid phase methods. The particle size of the liquid-phase-synthesized $\mathrm{Fe}_{0.5} \mathrm{Co}_{0.5} \mathrm{~S}_{2}$ is much smaller, which is expected to have a significant impact on discharge performance. In other words, larger specific surface area can greatly decrease electrochemical polarization, thus significantly slowing down the working voltage drop and improving discharge capacity. The discharge evaluation results in Fig. 10(e, f) show this tendency.

$\mathrm{Fe}_{0.5} \mathrm{Co}_{0.5} \mathrm{~S}_{2}$ cathodes have higher discharge capacity than an $\mathrm{FeS}_{2}$ cathode, which is due to the improved thermal stability provided by bimetallic Fe-Co. In addition, liquid phase synthesized $\mathrm{Fe}_{0.5} \mathrm{Co}_{0.5} \mathrm{~S}_{2}$ has a higher discharge capacity than solid-state synthesized $\mathrm{Fe}_{0.5} \mathrm{Co}_{0.5} \mathrm{~S}_{2}$. This is primarily due to the pure single-phase and small particle size of the aforementioned liquid phase synthesized $\mathrm{Fe}_{0.5} \mathrm{Co}_{0.5} \mathrm{~S}_{2}$. New approaches to take advantage of each substance, not limited to conventional disulfide cathodes, are very encouraging.

\section{4. $\mathrm{NiS}_{2}$}

The thermal stability of $\mathrm{NiS}_{2}$ is intermediate between that of $\mathrm{FeS}_{2}$ and $\mathrm{CoS}_{2}$, as shown in Fig. 11(a). ${ }^{4)}$ The electrochemical performance of $\mathrm{NiS}_{2}$ in an $\mathrm{LiCl}-\mathrm{KCl}$ eutectic electrolyte is compared to that of synthetic $\mathrm{FeS}_{2}$ and $\mathrm{CoS}_{2}$ in Fig. 11(b). As expected, the voltage response for the cell with the $\mathrm{NiS}_{2}$ cathode was intermediate between that of the $\mathrm{CoS}_{2}$ and $\mathrm{FeS}_{2}$ cells. However, the overall performance of the $\mathrm{NiS}_{2}$ cathode was similar to that of $\mathrm{CoS}_{2}$. Because the costs of $\mathrm{NiS}_{2}$ precursors are much less than those for $\mathrm{CoS}_{2}$, the similar electrochemical performance motivates the use of $\mathrm{NiS}_{2}$ for application where $\mathrm{CoS}_{2}$ might have been used. ${ }^{1-4)}$ However, $\mathrm{NiS}_{2}$ does not provide a cost advantage over $\mathrm{FeS}_{2}$ and is not attractive enough to offset the high cost in terms of performance. Several studies that expand on this point have been published.

To maximize the performance of $\mathrm{NiS}_{2}$, Zhou et al. fabricated $\mathrm{NiS}_{2}$ as a nanostructure and evaluated its properties and performance. ${ }^{22)}$ In this study, single cells composed of a nano- $\mathrm{NiS}_{2}$ cathode, an $\mathrm{LiCl}-\mathrm{LiBr}-\mathrm{LiF}$ electrolyte, and an $\mathrm{Li}$ $\mathrm{B}$ anode were fabricated and evaluated. All components were fabricated into pellet-type materials using a powder compaction process. Nanostructured $\mathrm{NiS}_{2}$ powders were prepared by ball-milling for 10 to $40 \mathrm{~h}$ and subsequently 

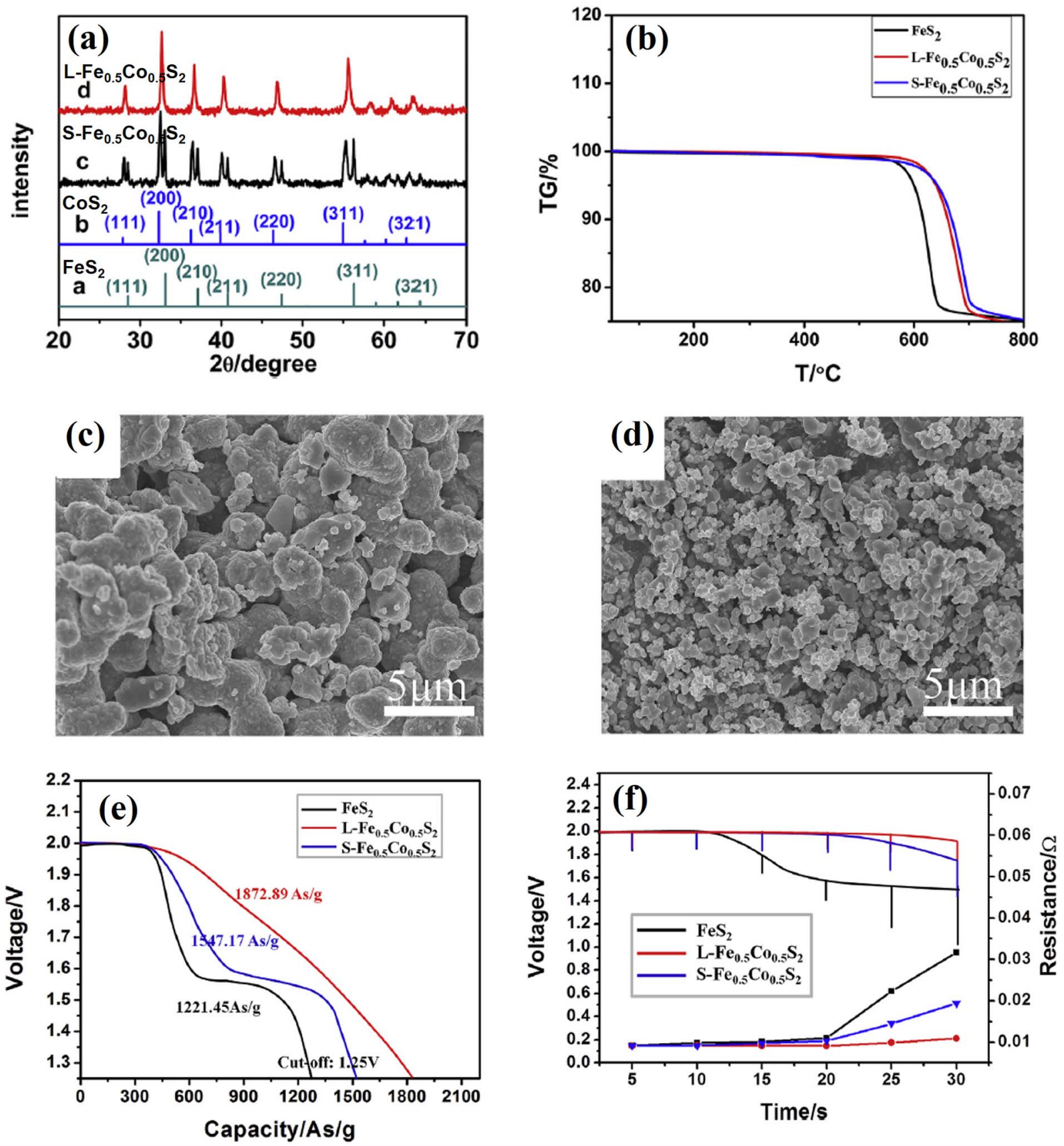

Fig. 10. (a) XRD patterns on $\mathrm{Fe}_{0.5} \mathrm{Co}_{0.5} \mathrm{~S}_{2}$ synthesized using two different methods. (b) Thermal analysis curves. SEM images of (c) $\mathrm{S}_{-} \mathrm{Fe}_{0.5} \mathrm{Co}_{0.5} \mathrm{~S}_{2}$ and (d) $\mathrm{L}-\mathrm{Fe}_{0.5} \mathrm{Co}_{0.5} \mathrm{~S}_{2}$. (e) Discharge curves for single cells. (f) Pulsed discharge curves and resistance change curves of single cells. Reprinted with permission from Ref. [20]. Copyright 2018 Elsevier B. V.

heating at $400^{\circ} \mathrm{C}$ for $1 \mathrm{~h}$ using carbonyl nickel and sulfur as precursors. The theoretical capacity of $\mathrm{NiS}_{2}$ is about 870 $\mathrm{mAh} / \mathrm{g}$, but the discharge capacity in practical applications is much lower. The sluggish diffusivity of lithium ions in the $\mathrm{NiS}_{2}$ cathode and low surface area of the bulk electrodes are identified as the primary factors producing poor discharge performance. ${ }^{93)}$ In addition, intermediate phase evolution with low conductivity can reduce the discharge performance. ${ }^{94,95)}$ In this study, the ball-milling time was defined as a control parameter to characterize the particle size of
$\mathrm{NiS}_{2}$. As shown in Fig. 12(b), the surface area of the $40 \mathrm{~h}$ ball-milled $\mathrm{NiS}_{2}$ is the largest, which can increase the contact area of the electrode and the electrolyte, thereby improving the discharge performance. The discharge capacity of $40 \mathrm{~h}$ ball-milled $\mathrm{NiS}_{2}$ was largest at the discharge curves $\left(0.1 \mathrm{~A} / \mathrm{cm}^{2}\right)$ shown in Fig. 12(c). The discharge curves $\left(0.5 \mathrm{~A} / \mathrm{cm}^{2}\right)$ in Fig. $12(\mathrm{~d})$ show the same tendency in the discharge capacity, but the voltage plateau becomes clearer. This is due to the intermediate phase generated during discharge, and it becomes clearer as the size of $\mathrm{NiS}_{2}$ particles 

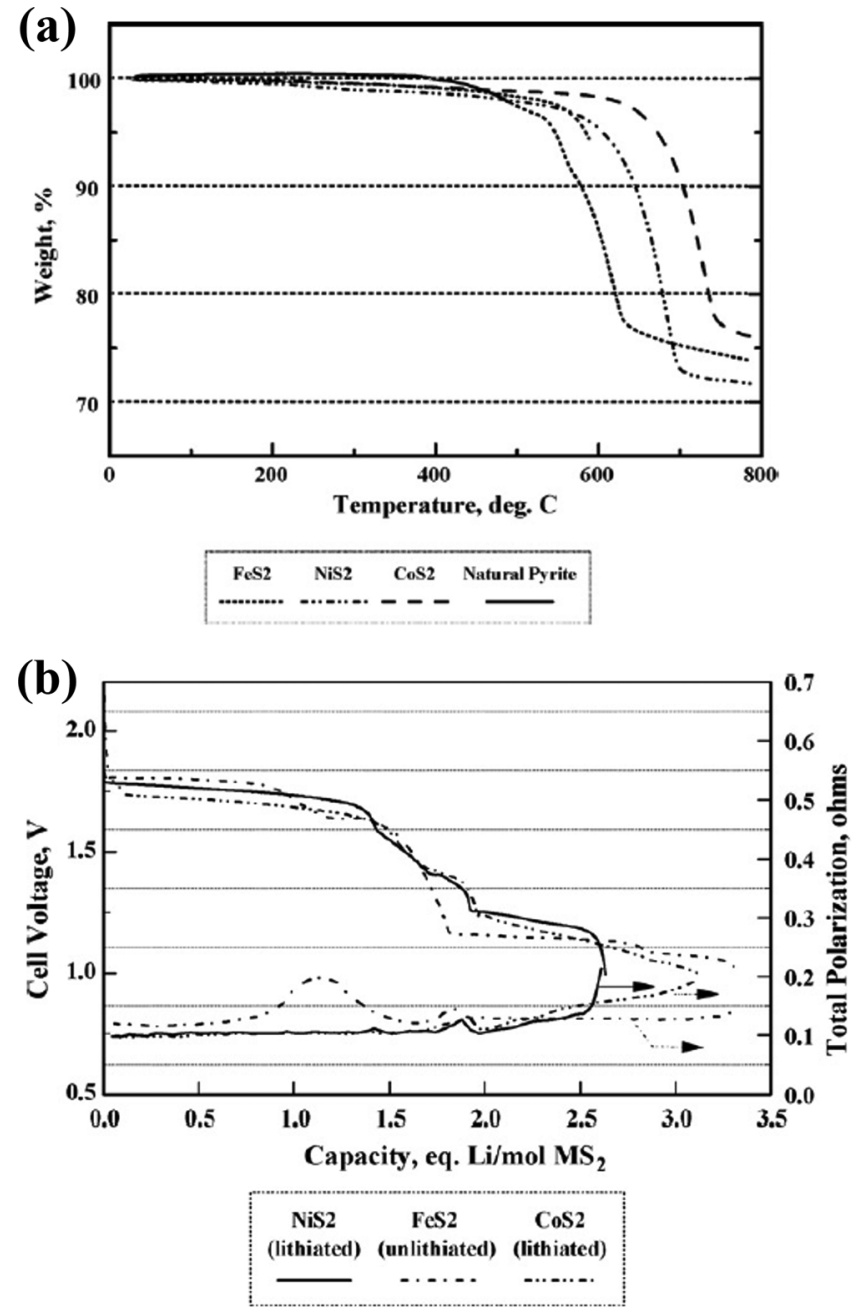

Fig. 11. (a) TGA traces for synthetic $\mathrm{FeS}_{2}, \mathrm{CoS}_{2}$, and $\mathrm{NiS}_{2}$ in argon. (b) Discharge of Li-Si/LiBr-KBr-LiCl/MS cells at $500^{\circ} \mathrm{C}$. Reprinted with permission from Ref. [4]. Copyright 2007 Elsevier B. V.

decreases. That is, if the size of $\mathrm{NiS}_{2}$ particles is large, the reaction mechanism of $\mathrm{NiS}_{2}$ does not occur completely. Inferred from the results of this study, the negative influence of the intermediate phase (NiS) becomes stronger when the $\mathrm{NiS}_{2}$ particles are larger due to the relatively low conductivity of $\mathrm{NiS},{ }^{96)}$ leading to a decrease in discharge performance. In other words, $\mathrm{NiS}_{2}$ produced rapid intermediate phase evolution, which increased the discharge capacity of the $\mathrm{NiS}_{2}$ cathode. This mechanism is shown in Fig. 12(a). This study is meaningful for improving the characteristics of the $\mathrm{NiS}_{2}$ cathode and for interpreting the performance improvement mechanism in various ways.

Zhou et al. studied carbon-modified nano- $\mathrm{NiS}_{2}$ based on the aforementioned nano- $\mathrm{NiS}_{2}$ results. ${ }^{23)}$ In this study, single cells composed of a carbon-coated nano- $\mathrm{NiS}_{2} /$ nano- $\mathrm{NiS}_{2}$ cathode, an $\mathrm{LiCl}-\mathrm{LiBr}-\mathrm{LiF}$ electrolyte, and an $\mathrm{Li}-\mathrm{B}$ anode were fabricated and evaluated. All components were fabricated into a pellet-type material using a powder compaction process. Carbon modification is always seen as an effective method for improving the conductivity and thermal/structural stability of electrodes. ${ }^{97-102)}$ In this study, $\mathrm{NiS}_{2}$ particles were coated with amorphous carbon. Then they accumulated into submicron particles and were connected/fixed by a carbon network. These effects are shown in Fig. 13(e, f), as shown in the TEM image and schematic diagram. The initial decomposition temperature of nano- $\mathrm{NiS}_{2}$ increased from 400 to $590^{\circ} \mathrm{C}$ after carbon modification. As shown in Fig. 13(b), the discharge performance improves as the thermal stability increases. In the case of carbon-coated nano-NiS $\mathrm{N}_{2}$, the discharge capacity at high temperature shows a stable specific capacity up to $600^{\circ} \mathrm{C}$ near the initial decomposition temperature (Fig. $13(\mathrm{c})$ ). Beyond $600^{\circ} \mathrm{C}, \mathrm{NiS}_{2}$ rapidly decomposes and its specific capacity decreases. Carbon modification not only improves the conductivity of the cathode on its own, but it also inhibits the spread of the low conductivity product $\mathrm{Li}_{2} \mathrm{~S}$. This effect is reflected in the pulse discharge and resistance results (Fig. 13(d)).

\section{5. $\mathrm{NiCl}_{2}$}

Due to several advantages mentioned above, disulfidebased materials have been used as the cathode in thermal batteries for decades. However, it is difficult for disulfide materials to meet recent demands for high power thermal batteries due to their low thermal stability and low discharge voltage. As a result, research and development on cathode materials (e.g., $\mathrm{NiCl}_{2}$ ) other than disulfide-based materials have continued. $\mathrm{NiCl}_{2}$ has been considered as one promising cathode material for use in thermal batteries thanks to its high relative potential, high current discharge, high specific energy, and low cost. However, its high solubility in molten salt electrolytes causes thermal batteries to short circuit, and its low electronic conductivity results in long activation time, thus $\mathrm{NiCl}_{2}$ thermal batteries cannot provide electrochemical performance. ${ }^{25)}$

Zhou et al. conducted surface modification with a carbon coating to improve the performance of $\mathrm{NiCl}_{2}$-based batteries. ${ }^{25)}$ It was confirmed that modification using carbon coating has a positive effect on electrochemical performance of $\mathrm{CoS}_{2}{ }^{18)}$ and $\mathrm{NiS}_{2} \cdot{ }^{23)}$ In this study, the solubility of $\mathrm{NiCl}_{2}$ in the molten salt was evaluated using a contact angle measurement on the $\mathrm{NiCl}_{2}$ cathode, which could be used to analyze wetting of the LiCl-LiBr-LiF electrolyte. These results indicate that the carbon coating could inhibit $\mathrm{NiCl}_{2}$ from dissolving into the molten salt (Fig. 14(a)). Single cells composed of carbon-coated nano- $\mathrm{NiCl}_{2} /$ pure $\mathrm{NiCl}_{2}$ cathodes, an LiCl-LiBr-LiF electrolyte, and an Li-B anode were fabricated and evaluated. All components were fabricated into pellet-type materials using a powder compaction process. The carbon-coated $\mathrm{NiCl}_{2}$ thermal batteries exhibited increased specific capacity and increased specific energy compared to that of pure $\mathrm{NiCl}_{2}$ thermal batteries.

Zhu et al. investigated an alternative to the conventional stainless steel substrate for $\mathrm{NiCl}_{2}$-based thermal batteries. ${ }^{26)}$ In this study, an $\mathrm{NiCl}_{2}$ cathode was fabricated by 
(a)

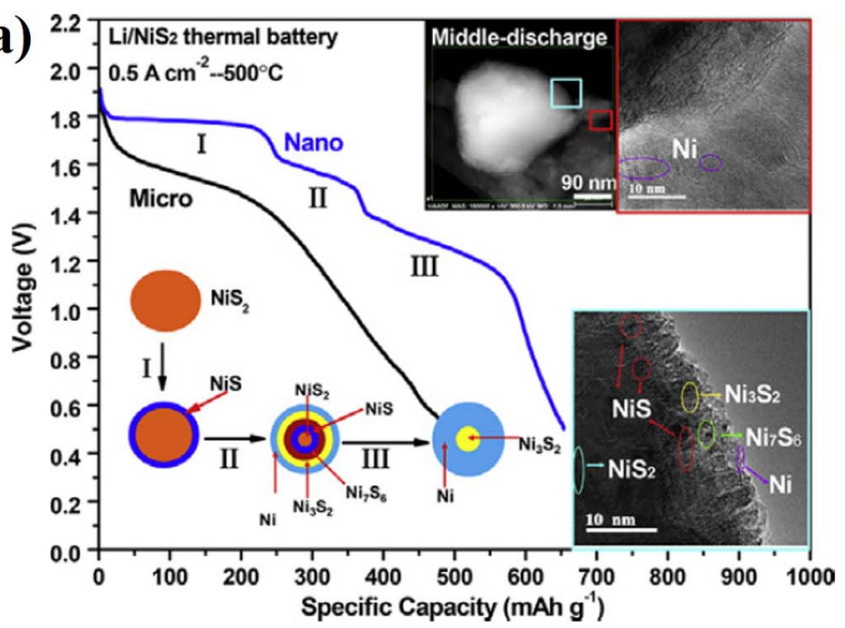

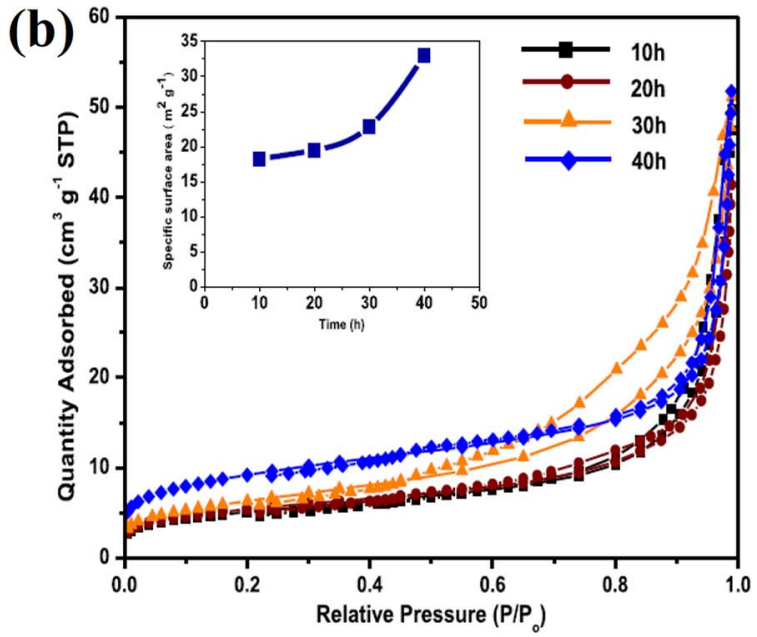

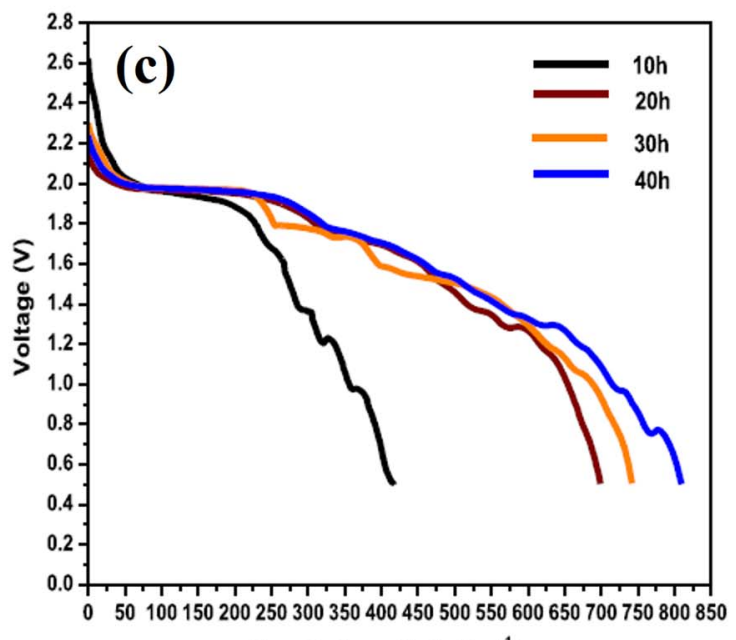

Specific Capacity ( $\left.\mathrm{mAh}^{-1}\right)$

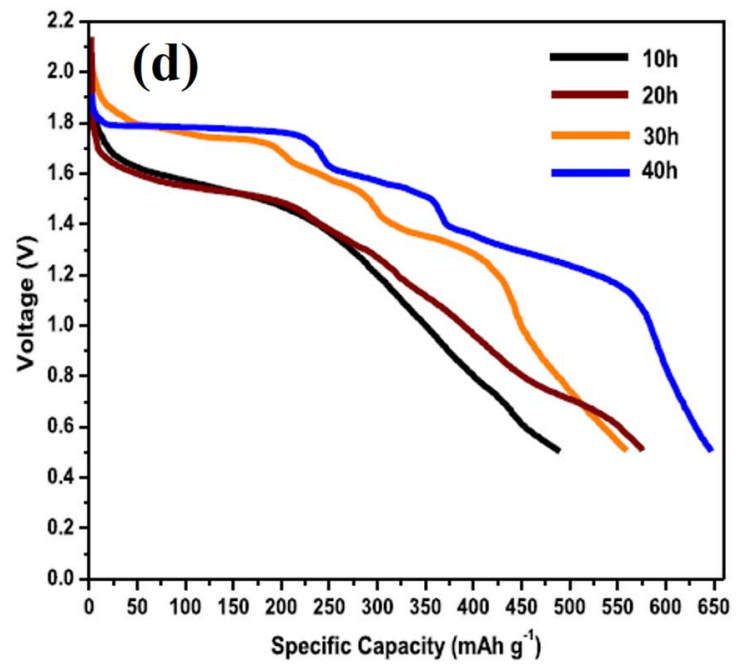

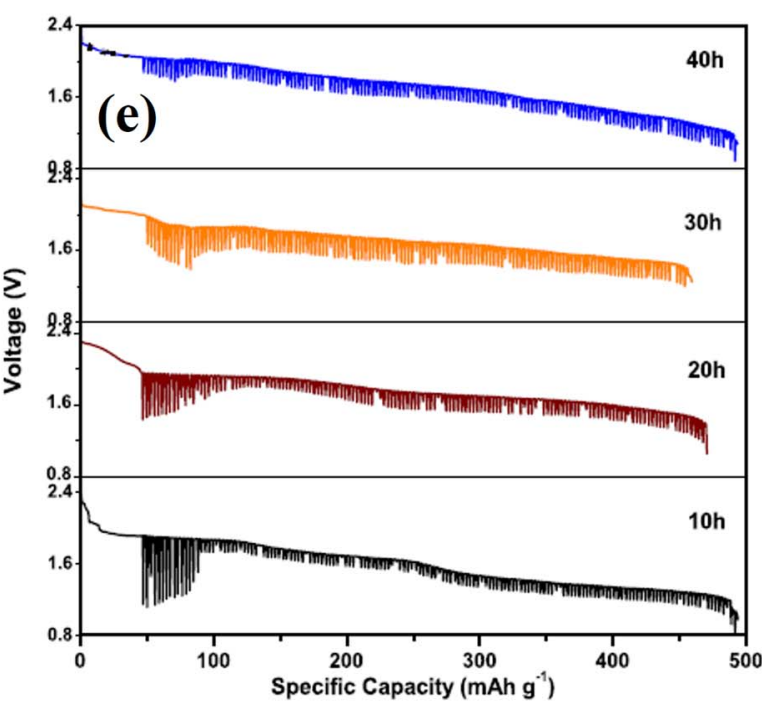

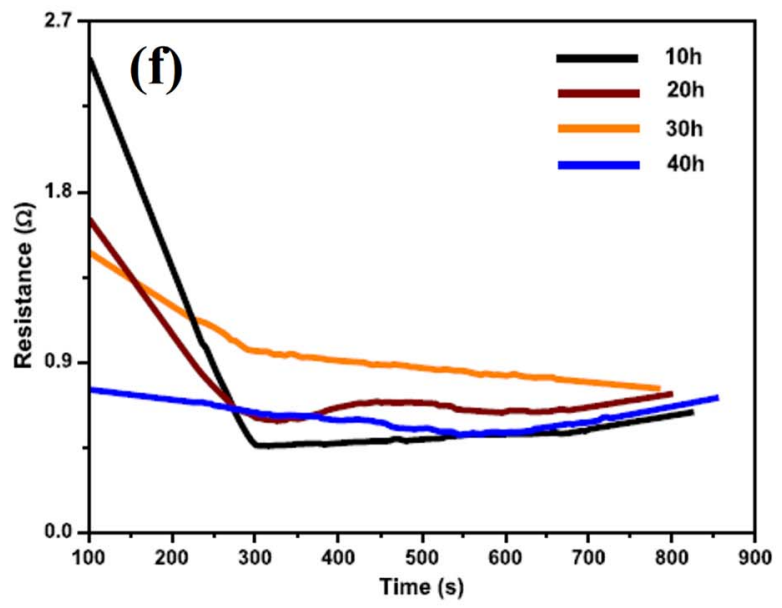

Fig. 12. (a) The effect of nano-NiS $\mathrm{S}_{2}$ in a thermal battery. (b) $\mathrm{N}_{2}$ adsorption-desorption isotherms (inset: BET surface area). Discharge performance of $\mathrm{NiS}_{2}$ with different ball-milling times at current densities of (c) $0.1 \mathrm{~A} / \mathrm{cm}^{2}$ and (d) $0.5 \mathrm{~A} / \mathrm{cm}^{2}$. (e) pulsed discharge performance. (f) Resistance variation. Reprinted with permission from Ref. [22]. Copyright 2017 Elsevier B. V.

screen printing on stainless steel and nickel foam substrates. In addition, $\mathrm{LiCl}-\mathrm{LiBr}-\mathrm{LiF}$ electrolyte and $\mathrm{Li}-\mathrm{Si}$ alloy anodes were fabricated into pellet-type materials using a powder compaction process. The shape of the $\mathrm{NiCl}_{2}$ cathode in Fig. 15(a,b) shows that $\mathrm{NiCl}_{2}$ penetrates the $\mathrm{Ni}$ foam. In Fig. 15(b), $\mathrm{NiCl}_{2}$ does not penetrate to the back of the $\mathrm{Ni}$ foam, 

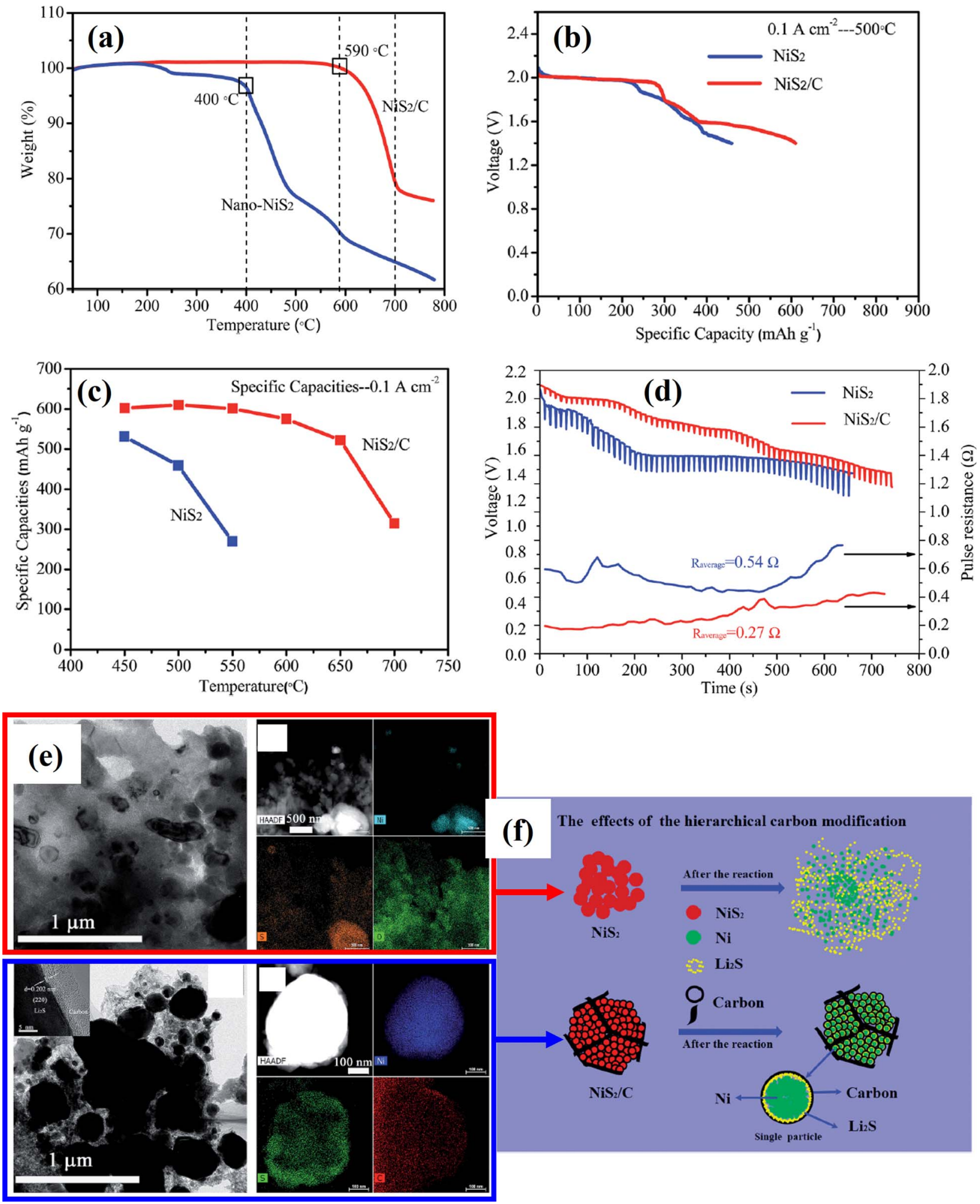

Fig. 13. (a) TG data from nano- $\mathrm{NiS}_{2}$ before and after carbon modification. (b-c) Specific capacities of $\mathrm{NiS}_{2}$ and $\mathrm{NiS} / \mathrm{C}$ at $0.1 \mathrm{~A} /$ $\mathrm{cm}^{2}$. (d) Pulse discharge and resistances. (e) TEM images of discharge products. (f) Schematic diagram showing carbon modification. Reprinted with permission from Ref. [23]. Copyright 2018 The Royal Society of Chemistry.

but this could be improved by adjusting the viscosity of the $\mathrm{NiCl}_{2}$ slurry and the screen-printing processing conditions. Furthermore, additional research on $\mathrm{Ni}$ foam may be needed because the porosity of the $\mathrm{Ni}$ foam and the shape of the pore can greatly affect the performance of the cathode. The peak voltage of the $\mathrm{NiCl}_{2}$ cathode using an $\mathrm{Ni}$ foam sub- 

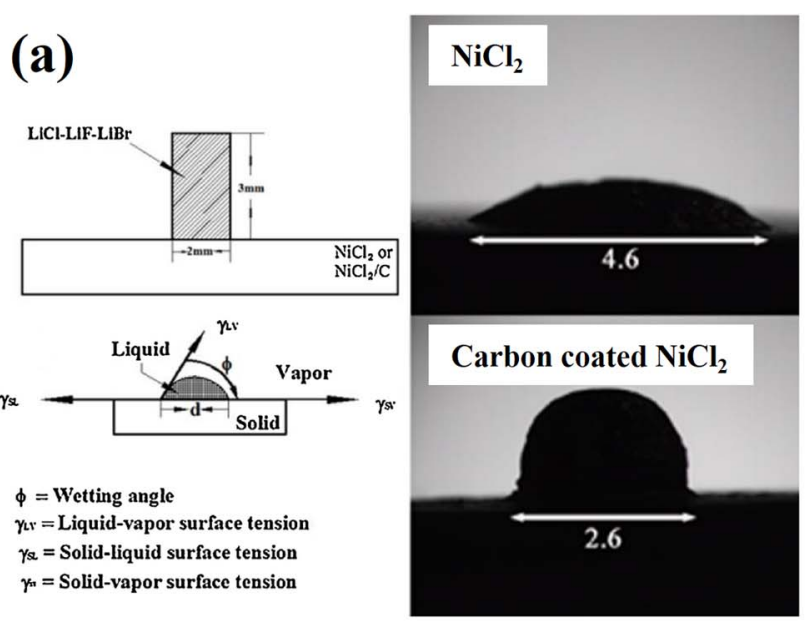
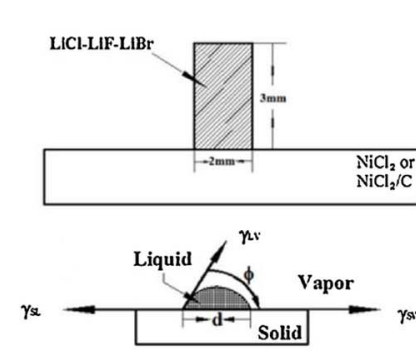

$\phi=$ Wetting angle

$\gamma_{\mathrm{L}}=$ Liquid-vapor surface tension

$\gamma_{\mathrm{s}}=$ Solid-liquid surface tension

$\gamma_{n}=$ Solid-vapor surface tension
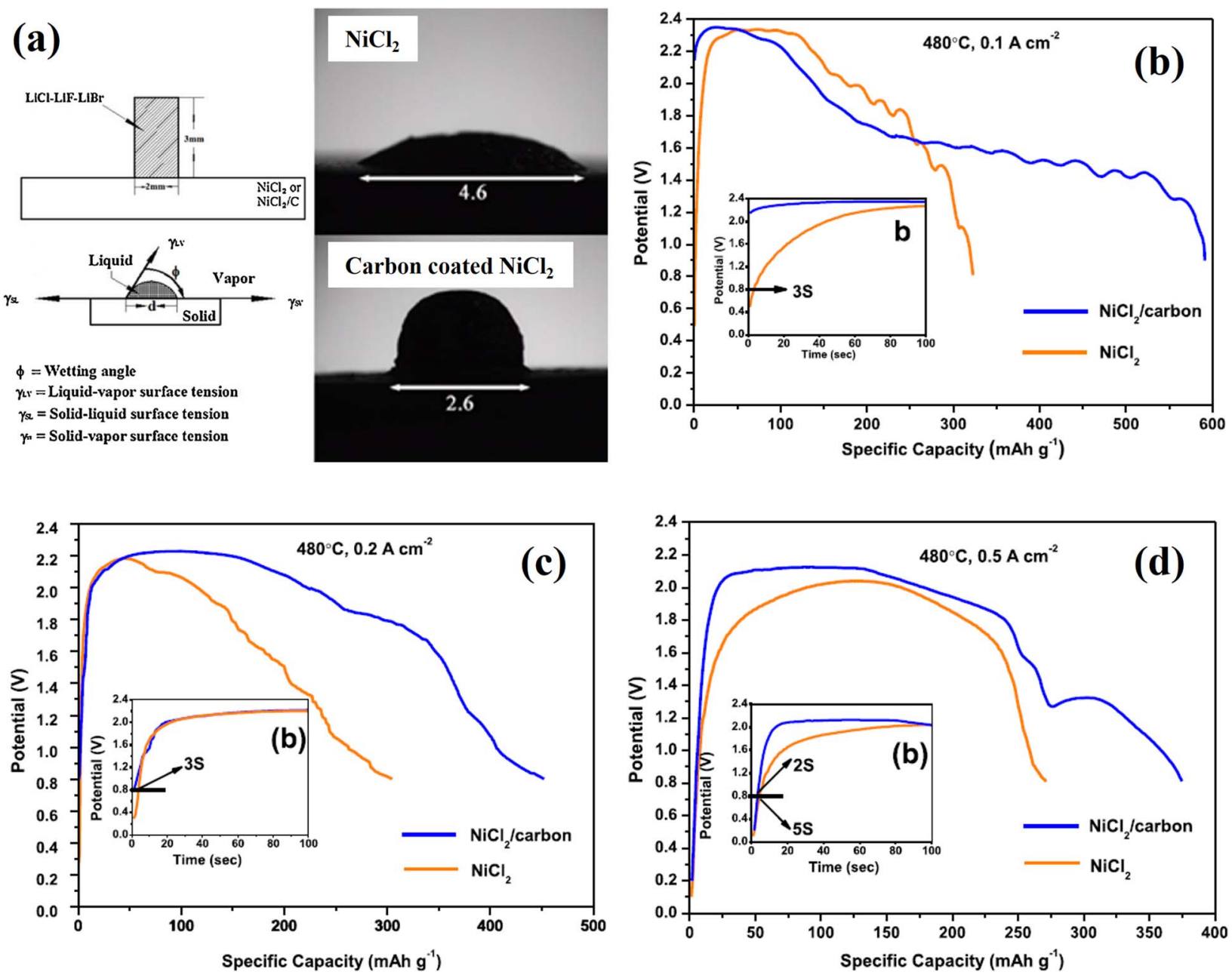

Fig. 14. (a) Contact angle test. (b-d) Comparison of the electrochemical performance of single-cell thermal batteries with carboncoated $\mathrm{NiCl}_{2}$ and pure $\mathrm{NiCl}_{2}$ cathodes at $480^{\circ} \mathrm{C}$ and at various current densities. Reprinted with permission from Ref. [25]. Copyright 2017 Elsevier B. V.

strate is about $2.55 \mathrm{~V}$, which is much higher than that of sulfide cathode materials. In addition, the $\mathrm{NiCl}_{2}$ cathode with a Ni foam substrate has a specific capacity of 684.61 $\mathrm{Asg}^{-1}$ with a cut-off voltage of $1.5 \mathrm{~V}$ (stainless steel substrate: $299.39 \mathrm{Asg}^{-1}$ ). This improvement can be attributed to the lower resistance of the $\mathrm{NiCl}_{2}$ cathode on the $\mathrm{Ni}$ foam substrate (Fig. 15(d)). It is significant that the results from this study can be used to improve the mass productivity of $\mathrm{NiCl}_{2}$ cathodes by using a metal foam substrate, which can greatly improve the electrochemical performance and screen printing process, making them suitable for mass production. This approach seems to be applicable to other cathode materials besides $\mathrm{NiCl}_{2}$, and it is important to consider the selection of suitable metal foams and shapes. In addition, because metal foam is expected to act as a support for the cathode material, it is also necessary to minimize the amount of binder material added to the slurry.

\section{Copper Vanadium Oxide}

Copper vanadium oxide provides high voltage, high capacity, and high thermal stability. $\mathrm{V}_{2} \mathrm{O}_{5}$ and $\mathrm{CuO}$ were previously evaluated for use as possible cathodes in thermal batteries. ${ }^{29)} \mathrm{In}$ addition, the electrochemistry of $\mathrm{Cu}_{5} \mathrm{~V}_{2} \mathrm{O}_{10}$ was reported by Sakurai et al. ${ }^{103)}$ and Eguchi et al.. ${ }^{104)}$

A series of the $\mathrm{CuO}-\mathrm{V}_{2} \mathrm{O}_{5}$ oxides, such as $\mathrm{CuV}_{2} \mathrm{O}_{6}$, $\mathrm{Cu}_{2} \mathrm{~V}_{2} \mathrm{O}_{7}$, and $\mathrm{Cu}_{5} \mathrm{~V}_{2} \mathrm{O}_{10}$ were synthesized and evaluated as possible candidate cathode materials in high voltage thermal batteries. ${ }^{29)}$ In this study, single cells composed of a copper vanadium oxide cathode, an $\mathrm{LiCl}-\mathrm{KCl}$ electrolyte, and an $\mathrm{Li}-\mathrm{Al}$ anode were fabricated and evaluated. All components were fabricated into pellet-type materials using a powder compaction process. In the Fig. 16(a), $\mathrm{Cu}_{2} \mathrm{~V}_{2} \mathrm{O}_{7}$ showed lower thermal stability than $\mathrm{CuV}_{2} \mathrm{O}_{6}$, but the weight loss was negligible $(0.085 \%)$ up to $600^{\circ} \mathrm{C}$. This is much smaller than the weight loss observed with sulfide cathode materials. A $3.4 \mathrm{~V}$ voltage plateau at a current density of $100 \mathrm{~mA} / \mathrm{g}$ and a $2.5 \mathrm{~V}$ voltage plateau at a current density of $310 \mathrm{~mA} / \mathrm{g}$ were observed during discharge at $525^{\circ} \mathrm{C}$. This is a much higher value than was observed with $\mathrm{FeS}_{2}$, which 
(a)
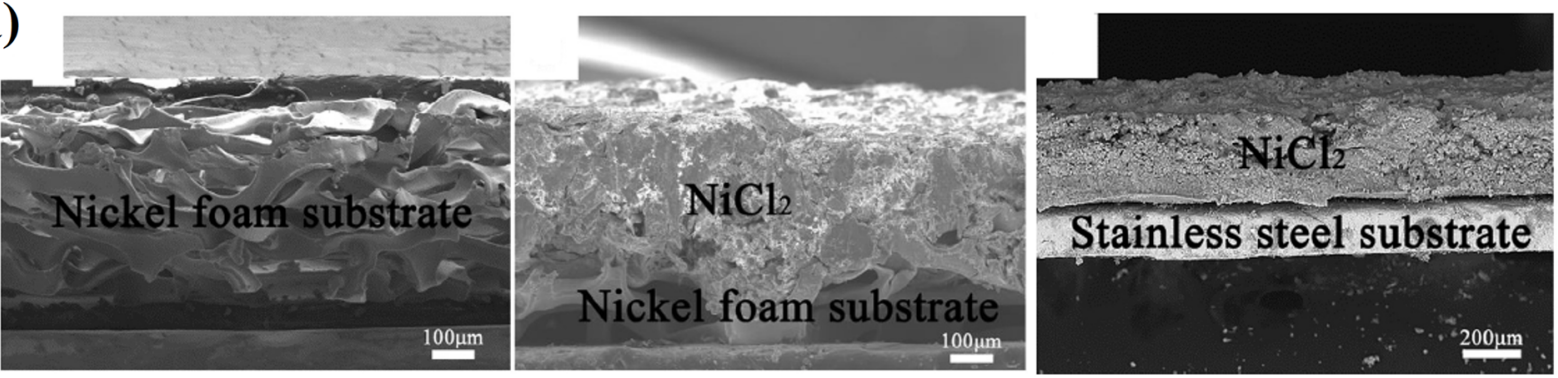

(b)

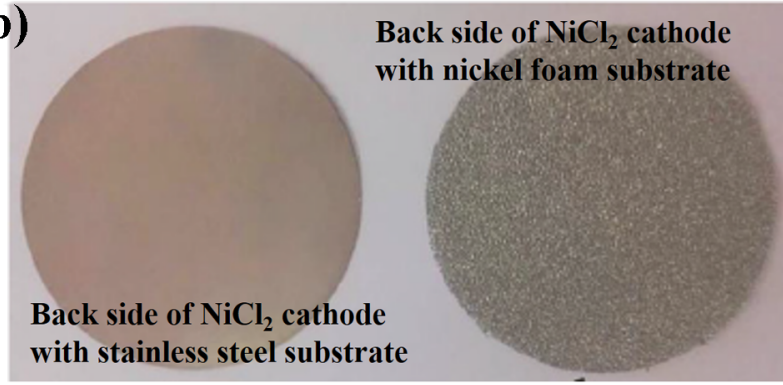

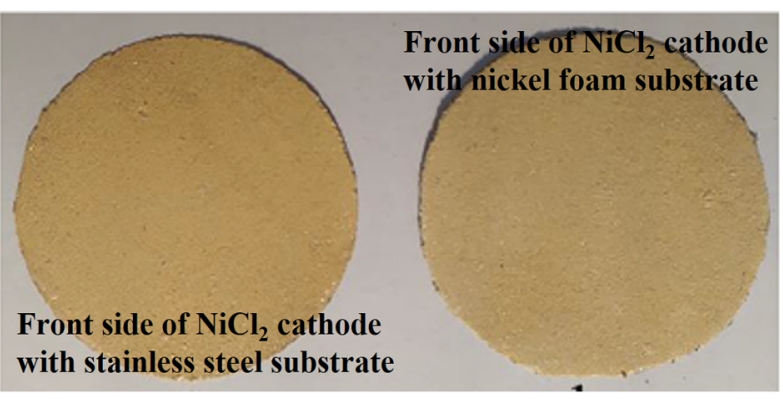

Front side of $\mathrm{NiCl}_{2}$ cathode with nickel foam substrate

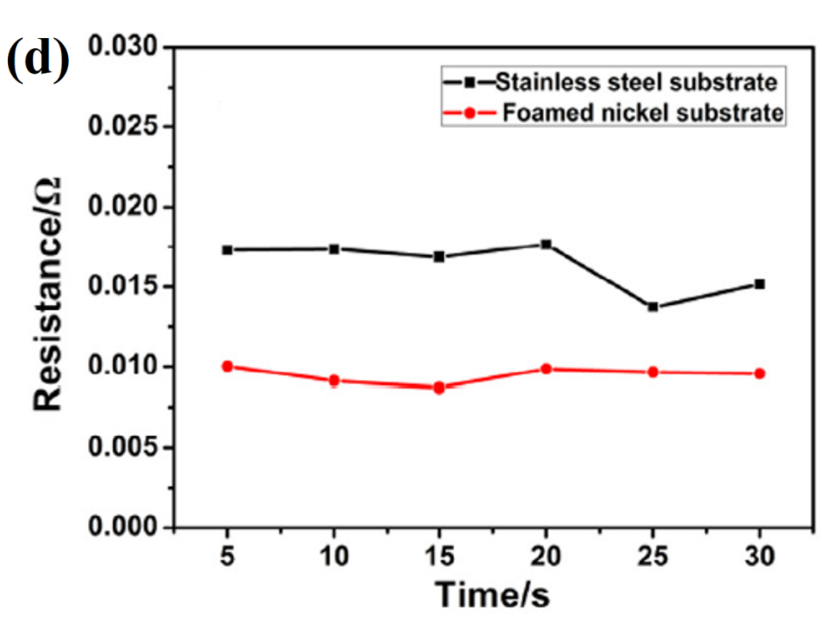

Fig. 15. (a) Photographs of the $\mathrm{NiCl}_{2}$ cathode. (b) Cross-sectional SEM images of the $\mathrm{NiCl}_{2}$ cathode. (c) Discharge curves and (d) resistance changes of single cells with $\mathrm{NiCl}_{2}$ cathodes. Reprinted with permission from Ref. [26]. Copyright 2017 Elsevier B. V.
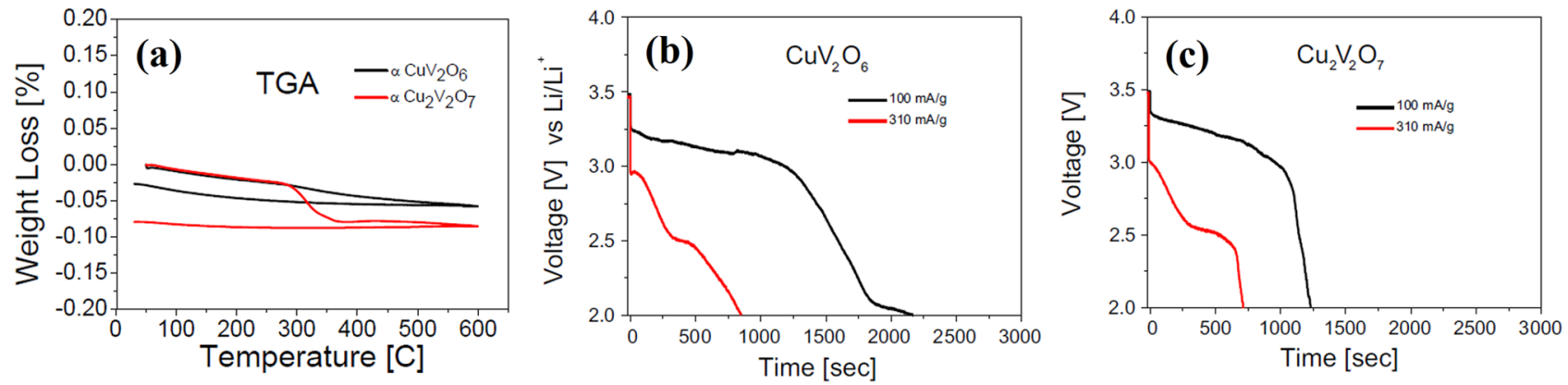

Fig. 16. (a) TGA curves of $\mathrm{CuV}_{2} \mathrm{O}_{6}$ and $\mathrm{Cu}_{2} \mathrm{~V}_{2} \mathrm{O}_{7}$. Discharge curves of the (b) $\mathrm{CuV}_{2} \mathrm{O}_{6}$ and (c) $\mathrm{Cu}_{2} \mathrm{~V}_{2} \mathrm{O}_{7}$ cathodes. Reprinted with permission from Ref. [29]. Copyright 2012 Elsevier B. V.

has a voltage plateau ranging from 1.5 to $2 \mathrm{~V}$ under similar conditions, and is a characteristic that can contribute to increasing the energy density.
Dai et al. studied $\mathrm{Cu}_{3} \mathrm{~V}_{2} \mathrm{O}_{8}$ and $\mathrm{Cu}_{5} \mathrm{~V}_{2} \mathrm{O}_{10}$ thin-film cathodes for thermal batteries. ${ }^{30)}$ In this study, single cells composed of a copper vanadium oxide cathode, a high-voltage 

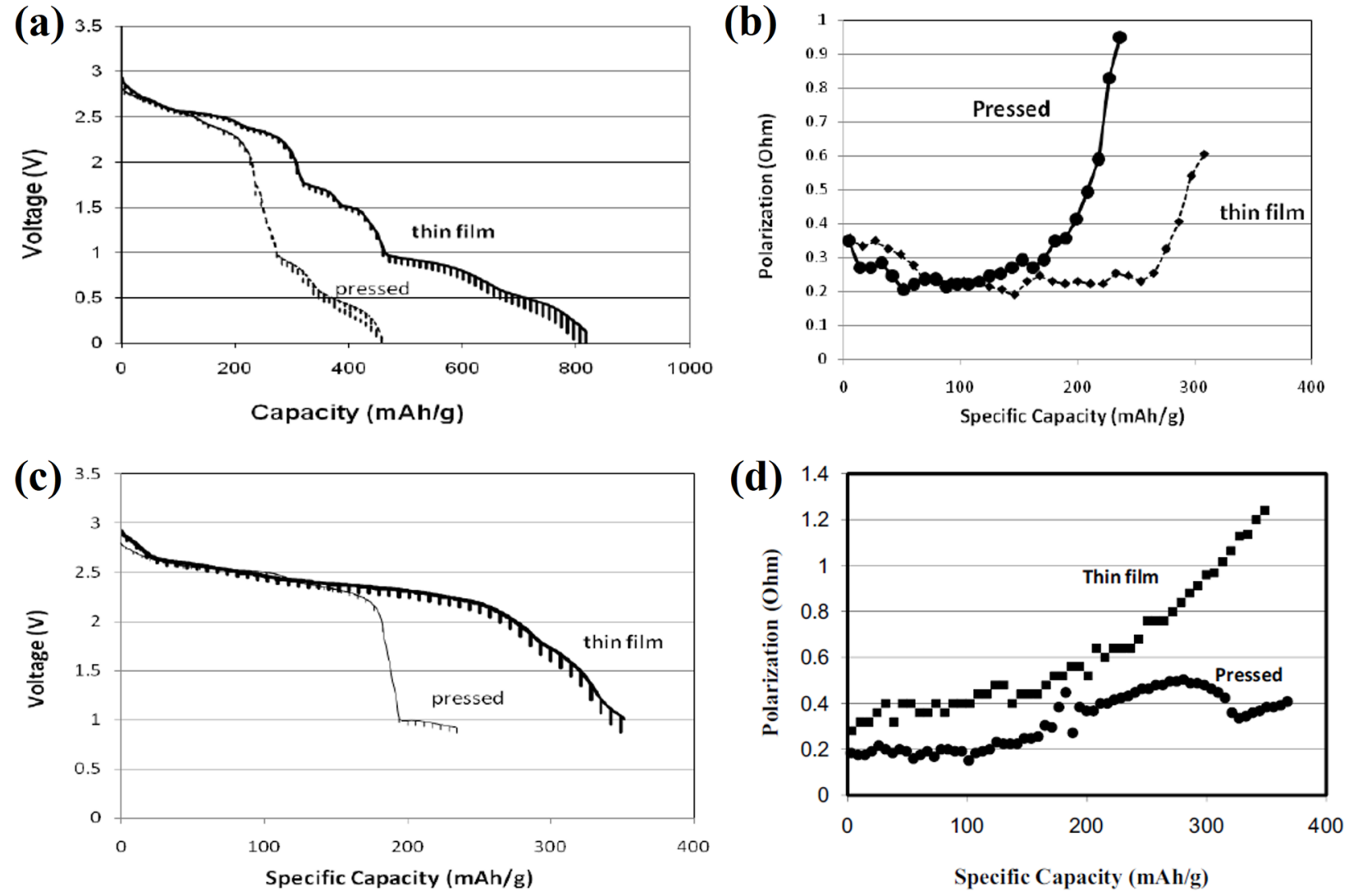

Fig. 17. (a) Discharge profile for an LiSi/Cu $\mathrm{Cu}_{5} \mathrm{O}_{10}$ cell. (b) Polarization of an LiSi/Cu $\mathrm{Cu}_{5} \mathrm{~V}_{2} \mathrm{O}_{10}$ cell. (c) Discharge profile of an LiSi/ $\mathrm{Cu}_{3} \mathrm{~V}_{2} \mathrm{O}_{8}$ cell. (d) Polarization of an LiSi/Cu $\mathrm{Cu}_{2} \mathrm{O}_{8}$ cell. Reprinted with permission from Ref. [30]. Copyright 2011 The Electrochemical Society.

compatible electrolyte, and an Li-Si anode were fabricated and evaluated. All components were fabricated into pellettype materials using a powder compaction process. The cathode was also fabricated as a thin film using tape casting in order to facilitate a suitable performance comparison. The high-voltage compatible electrolyte consists of $\mathrm{LiPO}_{3}$, $\mathrm{Li}_{2} \mathrm{SO}_{4}, \mathrm{Li}_{2} \mathrm{CO}_{3}$, and $\mathrm{LiF}$. Copper vanadium oxide has higher voltage than sulfide materials; therefore, it is necessary to study the molten salt electrolyte within a suitable voltage window. ${ }^{105)}$ In this study, the final constant stable open circuit voltage $(\mathrm{OCV})$ is $2.971 \mathrm{~V}$ at $500^{\circ} \mathrm{C}$. The discharge profile of the $\mathrm{Cu}_{5} \mathrm{~V}_{2} \mathrm{O}_{10}$ thin films contains multiple plateaus, similar to what was observed with a pressed film (Fig. 17(a)). The discharge profile of $\mathrm{Cu}_{3} \mathrm{~V}_{2} \mathrm{O}_{8}$ shows a much more obscure phase change than that of $\mathrm{Cu}_{5} \mathrm{~V}_{2} \mathrm{O}_{10}$. To determine the cause of these differences, an analysis of the discharge reaction for each substance would be necessary. The specific capacity of a thin film cathode is higher than that of a pressed cathode, regardless of the cathode materials.

Copper vanadium oxide has excellent properties, such as high voltage and high thermal stability, but studies on this material remain lacking. Applying the functional coating or manufacturing method mentioned above and optimizing the material properties were may significantly contribute to the development of thermal batteries with high energy density.

\section{Other Materials}

In addition to the aforementioned materials, other cathode materials for thermal batteries have been studied recently. Irvine et al. investigated $\mathrm{ZrS}_{3}$ as a possible cathode material for use in thermal batteries. ${ }^{31} \mathrm{ZrS}_{3}$ has a pseudo one-dimensional structure (Fig. 18(a)). In this study, single cells composed of a $\mathrm{ZrS}_{3}$ cathode, an $\mathrm{LiCl}-\mathrm{KCl}$ electrolyte, and an Li-Si anode were fabricated and evaluated. All components were fabricated into pellet-type materials using a powder compaction process. A single $1.7 \mathrm{~V}$ voltage plateau at a current density of $11 \mathrm{~mA} / \mathrm{cm}^{2}$ was observed during discharge at $500^{\circ} \mathrm{C}$ with a capacity of $357 \mathrm{mAh} / \mathrm{g}$. However, these results are inferior to existing sulfide materials, such as $\mathrm{FeS}_{2}, \mathrm{CoS}_{2}$ and $\mathrm{NiS}_{2}$. One thing to note is the high thermal stability of $700^{\circ} \mathrm{C}$. This study is an early attempt to apply $\mathrm{ZrS}_{3}$ as the cathode in thermal batteries, thus additional work should focus on improving the performance of these devices.

Irvine et al. investigated $\mathrm{CoNi}_{2} \mathrm{~S}_{4}$ as a candidate cathode material for use in thermal batteries. ${ }^{32)} \mathrm{CoNi}_{2} \mathrm{~S}_{4}$ adopts an inverse spinel structure, as shown in Fig. 18(d). In this study, single cells composed of a $\mathrm{CoNi}_{2} \mathrm{~S}_{4}$ cathode, an LiCl$\mathrm{KCl}$ electrolyte, and an $\mathrm{Li}-\mathrm{Si}$ anode were fabricated and evaluated. All components were fabricated into pellet-type 
(a)

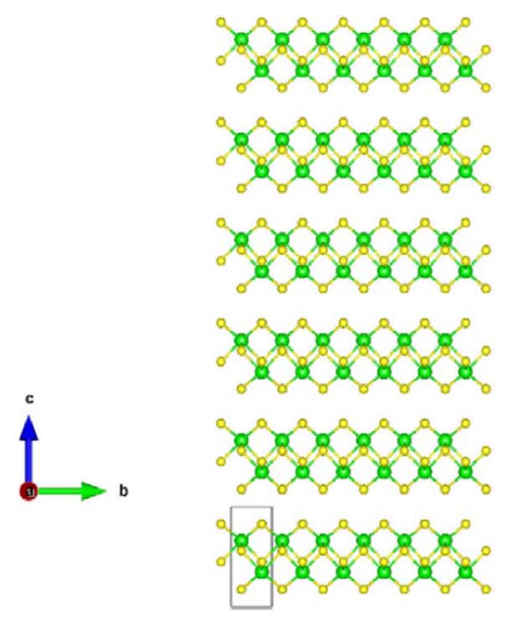

(b)

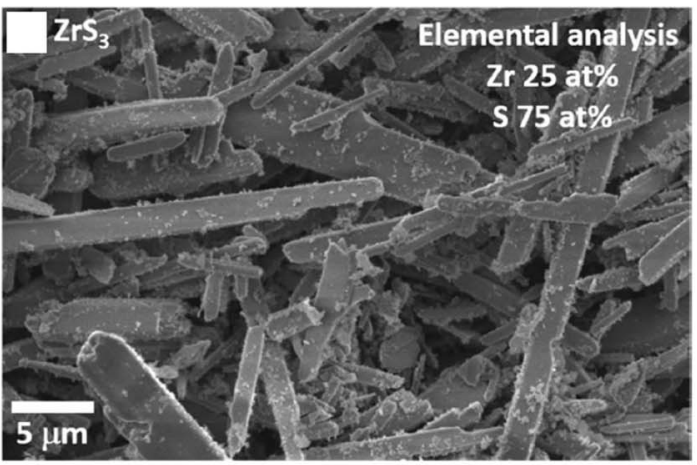

Capacity (mA h g $\left.{ }^{-1}\right)$

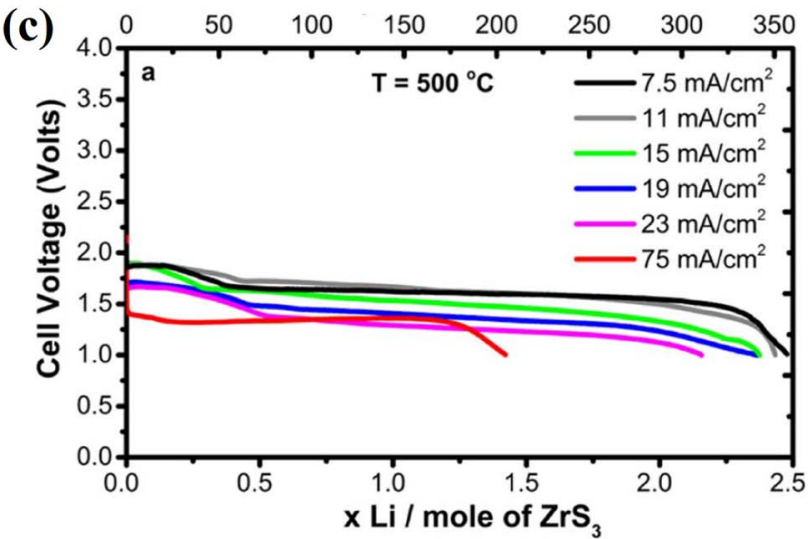

(d)

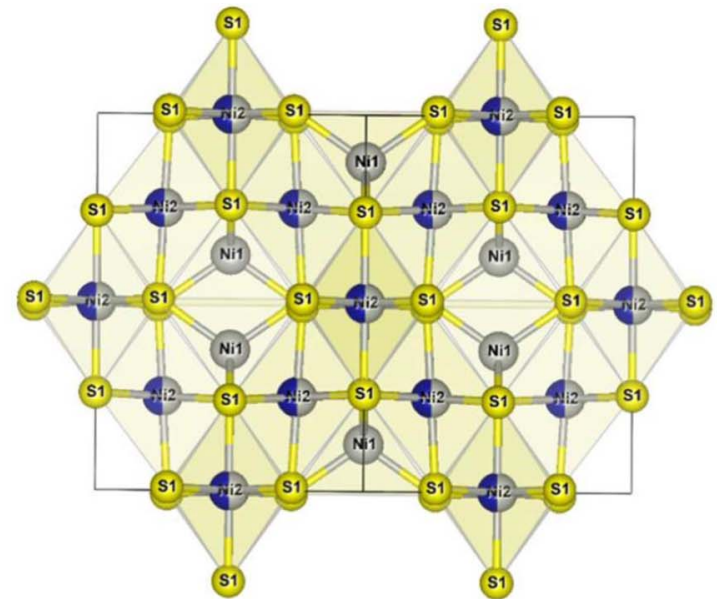

(e)

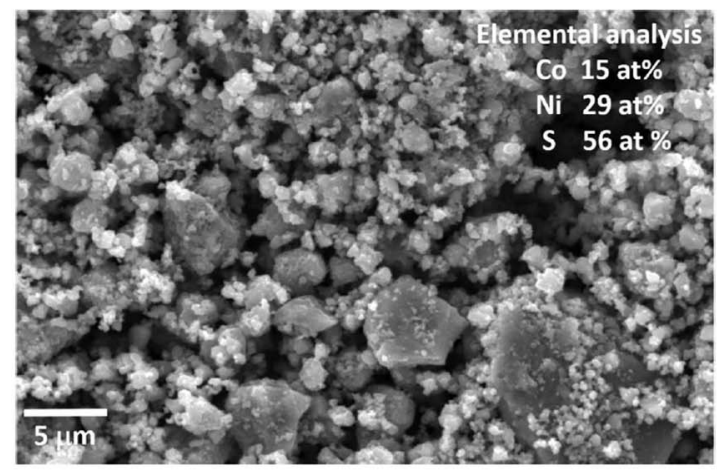

Capacity (mA h g $\left.{ }^{-1}\right)$

(f)

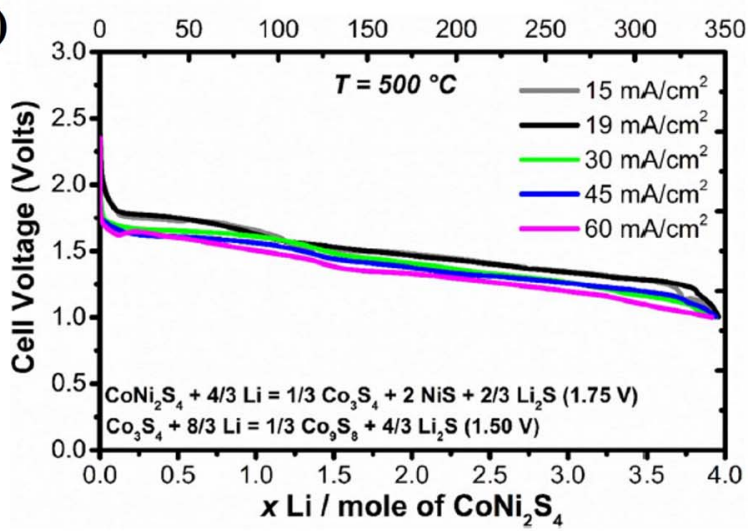

Fig. 18. (a) Crystal structure of $\mathrm{ZrS}_{3}$. (b) $\mathrm{SEM}$ image of a $\mathrm{ZrS}_{3}$ cathode. (c) Discharge performance of an LiSi/ $\mathrm{ZrS} \mathrm{S}_{3}$ cell. Reprinted with permission from Ref. [31]. Copyright: This is an open access article distributed under the Creative Commons Attribution License. (d) Crystal structure of $\mathrm{CoNi}_{2} \mathrm{~S}_{4}$. (e) $\mathrm{SEM}$ image of $\mathrm{CoNi}_{2} \mathrm{~S}_{4}$. (f) Discharge performance of an $\mathrm{LiSi} / \mathrm{CoNi}_{2} \mathrm{~S}_{4}$ cell. Reprinted with permission from Ref. [32]. Copyright: This is an open access article distributed under the Creative Commons Attribution License.

materials using a powder compaction process. The $\mathrm{CoNi}_{2} \mathrm{~S}_{4}$ cell exhibits two voltage plateaus at $500^{\circ} \mathrm{C}$, one at $1.75 \mathrm{~V}$ and the second at $1.5 \mathrm{~V}$. The $\mathrm{CoNi}_{2} \mathrm{~S}_{4}$ cell has a specific capacity of $318 \mathrm{mAh} / \mathrm{g}$ from 2.58 to $1.25 \mathrm{~V} \mathrm{OCV}$. However, these results are inferior to those mentioned above. $\mathrm{CoNi}_{2} \mathrm{~S}_{4}$ shows the thermal stability of $550^{\circ} \mathrm{C}$, which is lower than that of $\mathrm{FeS}_{2}$; hence, its application scope becomes even narrower.
It is encouraging that the development of new cathode materials for thermal batteries is ongoing. However, future studies should focus on improving the capacity, thermal stability, and voltage currently required in industry.

\section{Conclusions}

Thermal batteries are primarily limited to military appli- 
Table 1. Summary of Recent Studies on Cathode Materials for Thermal Batteries

\begin{tabular}{|c|c|c|c|c|c|c|c|c|c|c|c|}
\hline & Cathode & Anode & Electrolyte & $\begin{array}{c}\text { Cathode } \\
\text { type/Thickness } \\
(\mu \mathrm{m})\end{array}$ & $\begin{array}{l}\text { Specific } \\
\text { capacity } \\
(A \cdot \sec / g)\end{array}$ & $\begin{array}{c}\text { Discharge } \\
\text { temperature } \\
\left({ }^{\circ} \mathrm{C}\right)\end{array}$ & $\begin{array}{l}\text { Cut-off } \\
\text { (V) }\end{array}$ & $\begin{array}{l}\text { OCV } \\
\text { (V) }\end{array}$ & $\begin{array}{l}\text { Voltage } \\
\text { plateau } \\
\text { (V) }\end{array}$ & $\begin{array}{l}\text { Thermal } \\
\text { stability } \\
\left({ }^{\circ} \mathrm{C}\right)\end{array}$ & Ref \\
\hline 1 & $\mathrm{FeS}_{2}$ & $\mathrm{Li}-\mathrm{Si}$ & $\mathrm{LiCl}-\mathrm{KCl}$ & Pellet/ - & - & 500 & 1.56 & 1.9 & $1.75 / 1.5 / 1.1$ & 580 & {$[10]$} \\
\hline 2 & $\mathrm{FeS}_{2}$ & $\mathrm{Li}-\mathrm{Si}$ & $\mathrm{LiCl}-\mathrm{KCl}$ & Thin film/ 100 & 1934 & 500 & 1.3 & 2.0 & $1.75 / 1.4$ & 580 & {$[11]$} \\
\hline 3 & $\mathrm{FeS}_{2}$ & $\mathrm{Li}-\mathrm{Si}$ & $\mathrm{LiCl}-\mathrm{KCl}$ & Thin film/ 100 & 1283 & 500 & 1.3 & 1.9 & $1.8 / 1.4$ & 580 & {$[12]$} \\
\hline 4 & $\mathrm{FeS}_{2}$ & $\mathrm{Li}-\mathrm{Si}$ & $\mathrm{LiCl}-\mathrm{KCl}$ & Thin film/ 50 & 2305 & 500 & 1.3 & 2.0 & $1.85 / 1.4$ & 580 & {$[13]$} \\
\hline 5 & $\mathrm{CoS}_{2}$ & $\mathrm{Li}-\mathrm{Si}$ & LiCl-LiBr-LiF & Thin film/ 50 & 2092 & 500 & 1.25 & 1.99 & $1.9 / 1.76$ & 650 & {$[16]$} \\
\hline 6 & $\mathrm{CoS}_{2}$ & $\mathrm{Li}-\mathrm{Si}$ & $\mathrm{LiCl}-\mathrm{KCl}$ & Pellet/ - & 791.28 & 500 & 1.7 & 1.84 & $1.77 / 1.3$ & 650 & {$[17]$} \\
\hline 7 & $\mathrm{CoS}_{2}$ & $\mathrm{Li}-\mathrm{Si}$ & $\mathrm{LiCl}-\mathrm{KCl}$ & Pellet/ - & 848.88 & 500 & 1.7 & 1.84 & $1.78 / 1.3$ & 650 & {$[18]$} \\
\hline 8 & $\mathrm{Co}_{0.3} \mathrm{Fe}_{0.7} \mathrm{~S}_{2}$ & $\mathrm{Li}-\mathrm{Si}$ & $\mathrm{LiCl}-\mathrm{KCl}$ & Pellet/ - & 2304 & 525 & 1.0 & 2 & $1.85 / 1.3$ & 620 & {$[19]$} \\
\hline 9 & $\mathrm{Fe}_{0.5} \mathrm{Co}_{0.5} \mathrm{~S}_{2}$ & $\mathrm{Li}-\mathrm{Si}$ & LiCl-LiBr-LiF & Thin film/ 50 & 1872.89 & - & 1.25 & 2.04 & 2 & 620 & {$[20]$} \\
\hline 10 & $\mathrm{NiS}_{2}$ & $\mathrm{Li}-\mathrm{B}$ & LiCl-LiBr-LiF & Pellet/ - & 2858.4 & 500 & 0.5 & 2.2 & $1.98 / 1.8 / 1.4$ & 400 & {$[22]$} \\
\hline 11 & $\mathrm{NiS}_{2}$ & $\mathrm{Li}-\mathrm{B}$ & LiCl-LiBr-LiF & Pellet/ - & 2196 & 500 & 1.4 & 2.0 & $2.0 / 1.6$ & 590 & {$[23]$} \\
\hline 12 & $\mathrm{NiCl}_{2}$ & $\mathrm{Li}-\mathrm{B}$ & LiCl-LiBr-LiF & Pellet/ - & 2127.6 & 480 & 0.8 & 2.35 & $2.3 / 1.5$ & - & {$[25]$} \\
\hline 13 & $\mathrm{NiCl}_{2}$ & $\mathrm{Li}-\mathrm{Si}$ & LiCl-LiBr-LiF & $\begin{array}{l}\text { Nickel foam/ } \\
400\end{array}$ & 684.61 & - & 1.5 & 2.55 & - & - & {$[26]$} \\
\hline 14 & $\mathrm{CuV}_{2} \mathrm{O}_{6}$ & $\mathrm{Li}-\mathrm{Al}$ & $\mathrm{LiCl}-\mathrm{KCl}$ & Pellet/ 1000 & 220 & 525 & 2.0 & 3.5 & - & 600 & {$[29]$} \\
\hline 15 & $\mathrm{Cu}_{2} \mathrm{~V}_{2} \mathrm{O}_{7}$ & $\mathrm{Li}-\mathrm{Al}$ & $\mathrm{LiCl}-\mathrm{KCl}$ & Pellet/ 1000 & 125 & 525 & 2.0 & 3.5 & - & 600 & {$[29]$} \\
\hline 16 & $\mathrm{Cu}_{5} \mathrm{~V}_{2} \mathrm{O}_{10}$ & $\mathrm{Li}-\mathrm{Si}$ & $\begin{array}{l}\mathrm{LiPO}_{3}, \mathrm{LiSO}_{4} \\
\mathrm{Li}_{2} \mathrm{CO}_{3}, \mathrm{LiF}\end{array}$ & Thin film/ 80 & 1044 & 500 & 2.0 & 2.971 & $2.5 / 1.75 / 1.5$ & - & {$[30]$} \\
\hline 17 & $\mathrm{Cu}_{3} \mathrm{~V}_{2} \mathrm{O}_{8}$ & $\mathrm{Li}-\mathrm{Si}$ & $\begin{array}{c}\mathrm{LiPO}_{3}, \mathrm{LiSO}_{4}, \\
\mathrm{Li}_{2} \mathrm{CO}_{3}, \mathrm{LiF}\end{array}$ & Thin film/ 80 & 990 & 500 & 2.0 & 2.971 & 2.4 & - & {$[30]$} \\
\hline 18 & $\mathrm{ZrS}_{3}$ & $\mathrm{Li}-\mathrm{Si}$ & $\mathrm{LiCl}-\mathrm{KCl}$ & Pellet/ - & 1285.2 & 500 & 1.0 & 1.8 & 1.7 & 700 & {$[31]$} \\
\hline 19 & $\mathrm{CoNi}_{2} \mathrm{~S}_{4}$ & $\mathrm{Li}-\mathrm{Si}$ & $\mathrm{LiCl}-\mathrm{KCl}$ & Pellet/ - & 1144.8 & 500 & 1.25 & 2.58 & - & 500 & {$[32]$} \\
\hline
\end{tabular}

cations because of their specificity. This closed and specific propensity is reflected in research activities, and the number of published studies is very small compared to studies on general $\mathrm{Li}$ ion batteries. Nevertheless, over the past decade, much valuable research has been conducted on cathode materials for thermal batteries. Table 1 summarizes the main results of recent studies. Today, electronics industries in all fields are rapidly developing, and demand for power sources with high energy density is increasing. The military requires a high-performance power source that can power advanced weapons systems. In other words, future thermal batteries require high energy density and high reliability against external stimuli.

High capacity, high voltage, and high thermal stability are the three most important considerations for the development of high performance thermal batteries. There are four major approaches to improve these.

I. Surface modification: Coating with carbon or other materials to improve the thermal stability or electrical conductivity of conventional cathode materials.

II. Alloy and compound: Synthesis of alloy or compound materials to improve the thermal stability or specific capacity of conventional cathode materials.

III. Manufacturing method: Manufacturing of a thin film cathode to overcome the limitations of pellet-type materials formed via powder compaction.
IV. New materials

It would be possible to develop a cathode for high performance thermal batteries by appropriately combining the above considerations.

\section{Acknowledgments}

This research was supported by 'Agency for Defense Development' (2019-0060) as a collaborative core technology research project.

\section{REFERENCES}

1. R. A. Guidotti and P. Masset, "Thermally Activated (“Thermal") Battery Technology Part I: An Overview," J. Power Sources, 161 [2] 1443-49 (2006).

2. P. Masset and R. A. Guidotti, "Thermally Activated ("Thermal") Battery Technology Part II: Molten Salt Electrolytes," J. Power Sources, 164 [1] 397-414 (2007).

3. P. J. Masset and R. A. Guidotti, "Thermally Activated ("Thermal") Battery Technology Part IIIa: $\mathrm{FeS}_{2}$ Cathode Material," J. Power Sources, 177 [2] 595-609 (2008).

4. P. J. Masset and R. A. Guidotti, "Thermally Activated ("Thermal") Battery Technology Part IIIb: Sulfur and Oxide-based Cathode Materials," J. Power Sources, 178 [1] 456-66 (2008).

5. R. A. Guidotti and P. J. Masset, "Thermally Activated 
(“Thermal”) Battery Technology Part IV: Anode Materials," J. Power Sources, 183 [1] 388-98 (2008).

6. S. S. Wang and R. N. Seefurth, "Electrochemical Studies of $\mathrm{FeS}_{2}$ Electrodes in Various Sulfide-Containing Molten Salts," J. Electrochem. Soc., 134 [3] 530-35 (1987).

7. S. H. Chae, S. H. Kang, H. W. Cheong, Y. S. Han, and D. H. Yoon, "Thermal Batteries with Ceramic Felt Separators - Part 1: Wetting, Loading Behavior and Chemical Stability," Ceram. Int., 43 [5] 4015-22 (2017).

8. S. H. Kang, S. H. Chae, H. W. Cheong, K. H. Kim, Y. S. Han, S. M. Lee, D. H. Yoon, and J. Yi, "Thermal Batteries with Ceramic Felt Separators - Part 2: Ionic Conductivity, Electrochemical and Mechanical Properties," Ceram. Int., 43 [5] 4023-28 (2017).

9. Y. S. Choi, H. R. Yu, and H. W. Cheong, "Electrochemical Properties of a Lithium-Impregnated Metal Foam Anode for Thermal Batteries," J. Power Sources, 276 102-4 (2015).

10. Y. Choi, S. Cho, and Y. S. Lee, "Effect of the Addition of Carbon Black and Carbon Nanotube to $\mathrm{FeS}_{2}$ Cathode on the Electrochemical Performance of Thermal Battery," $J$. Ind. Eng. Chem., 20 [5] 3584-89 (2014).

11. J. Ko, I. Y. Kim, H. M. Jung, H. Cheong, and Y. S. Yoon, "Thin Cathode for Thermal Batteries Using a Tape Casting Process," Ceram. Int., 43 [7] 5789-93 (2017).

12. I. Oh, J. Cho, K. Kim, J. Ko, H. Cheong, Y. S. Yoon, and H. M. Jung, "Poly(Imide-co-Siloxane) as a Thermo-Stable Binder for Thin Layer Cathode of Thermal Batteries," Energies, 11 [11] 3154 (2018).

13. J. Ko, I. Y. Kim, H. Cheong, and Y. S. Yoon, "Organic Binder-free Cathode Using $\mathrm{FeS}_{2}$-MWCNTs Composite for Thermal Batteries," J. Am. Ceram. Soc., 100 [10] 4435-41 (2017).

14. T. Yang, L. Cai, and R. E. White, "Mathematical Modeling of the $\mathrm{LiAl} / \mathrm{FeS}_{2}$ High Temperature Battery System," J. Power Sources, 201 322-31 (2012).

15. E. L. Reinholz, S. A. Roberts, C. A. Apblett, J. B. Lechman, and P. R. Schunk, "Composition and Manufacturing Effects on Electrical Conductivity of $\mathrm{Li} / \mathrm{FeS}_{2}$ Thermal Battery Cathode," J. Electrochem. Soc., 163 [8] A1723-29 (2016).

16. J. Hu, Y. Chu, Q. Tian, J. Wang, Y. Li, Q. Wu, L. Zhao, and Y. Zhu, "Film Cathode for Thermal Batteries Using a Screen-Printing Process," Mater. Lett., 215 296-99 (2018).

17. S. Xie, Y. Deng, J. Mei, Z. Yang, W. M. Lau, and H. Liu, "Facile Synthesis of $\mathrm{CoS}_{2} / \mathrm{CNTS}_{\mathrm{S}}$ Composite and its Exploitation in Thermal Battery Fabrication," Composites, Part B, 93 203-9 (2016).

18. S. Xie, Y. Deng, J. Mei, Z. Yang, W. M. Lau, and H. Liu, "Carbon Coated $\mathrm{CoS}_{2}$ Thermal Battery Electrode Material with Enhanced Discharge Performances and Air Stability," Electrochim. Acta, 231 287-93 (2017).

19. T. Yu, Z. Yu, Y. Cao, H. Liu, X. Liu, Y. Cui, C. Wang, and Y. Cui, "Electrochemical Performances and Air Stability of Fe-deped $\mathrm{CoS}_{2}$ Cathode Materials for Thermal Batteries," Int. J. Electrochem. Sci., 13 7590-97 (2018).

20. J. Hu, L. Zhao, Y. Chu, Q. Tian, J. Wang, Y. Li, Q. Wu, and Y. Zhu, "Preparation and Electrochemical Properties of a New $\mathrm{Fe}_{0.5} \mathrm{Co}_{0.5} \mathrm{~S}_{2}$ Cathode Material for Thermal Bat- teries," J. Alloys Compd., 762 109-114 (2018).

21. Y. Xie, Z. Liu, H. Ning, H. Huang, and L. Chen, "Suppressing Self-Discharge of $\mathrm{Li}-\mathrm{B} / \mathrm{CoS}_{2}$ Thermal Batteries by Using a Carbon-Coated $\mathrm{CoS}_{2}$ Cathode," RSC Adv., 8 [13] 7173-78 (2018).

22. C. Jin, L. Zhou, L. Fu, J. Zhu, D. Li, and W. Yang, "The Acceleration Intermediate Phase (NiS and $\mathrm{Ni}_{3} \mathrm{~S}_{2}$ ) Evolution by Nanocrystallization in $\mathrm{Li} / \mathrm{NiS}_{2}$ Thermal Batteries with High Specific Capacity," J. Power Sources, 352 83-9 (2017).

23. C. Jin, L. Fu, J. Zhu, W. Yang, D. Li, and L. Zhou, "A Hierarchical Carbon Modified Nano- $\mathrm{NiS}_{2}$ Cathode with High Thermal Stability for a High Energy Thermal Battery," J. Mater. Chem. A, 6 [16] 7123-32 (2018).

24. J. L. Payne, J. D. Percival, K. Giagloglou, C. J. Crouch, G. M. Carins, R. I. Smith, R. Comrie, R. K. B. Gover, and J. T. S. Irvine, "In-situ Thermal Battery Discharge Using $\mathrm{NiS}_{2}$ as a Cathode Material," ChemElectroChem, 4 [8] 1-9 (2017).

25. C. Jin, L. Zhou, L. Fu, J. Zhu, and D. Li, "Synthesis and Discharge Performances of $\mathrm{NiCl}_{2}$ by Surface Modification of Carbon Coating as Cathode Material of Thermal Battery," Appl. Surf. Sci., 402 308-13 (2017).

26. J. Hu, Y. Chu, Q. Tian, S. Guo, M. Yang, X. Wang, L. Zhao, and Y. Zhu, "Electrochemical Properties of the $\mathrm{NiCl}_{2}$ Cathode with Nickel Foam Substrate for Thermal Batteries," Mater. Lett., 207 198-201 (2017).

27. W. Liu, H. Liu, S. Bi, L. Cao, and Y. Sun, "Variable-Temperature Preparation and Performance of $\mathrm{NiCl}_{2}$ as a Cathode Material for Thermal Batteries," Sci. China Mater., 60 [3] 251-57 (2017).

28. K. Giagloglou, J. L. Payne, C. Crouch, R. K. B. Gover, P. A. Connor, and J. T. S. Irvine, "Transition Metal Chlorides $\mathrm{NiCl}_{2}, \mathrm{KNiCl}_{3}, \mathrm{Li}_{6} \mathrm{VCl}_{8}$ and $\mathrm{Li}_{2} \mathrm{MnCl}_{4}$ as Alternative Cathode Materials in Primary Li Thermal Batteries," J. Electrochem. Soc., 165 [14] A3510-16 (2018).

29. T. Hillel and Y. Ein-Eli, "Copper Vanadate as Promising High Voltage Cathodes for Li Thermal Batteries," $J$. Power Sources, 229 112-16 (2013).

30. J. Dai, M. Lai, R. LaFollette, and D. Reisner, "Thin Film Copper Vanadium Oxide Electrodes for Thermal Batteries," ECS Trans., 33 [27] 3-9 (2011).

31. K. Giagloglou, J. L. Payne, C. Crouch, R. K. B. Gover, P. A. Connor, and J. T. S. Irvine, "Zirconium Trisulfide as a Promising Cathode Material for Li Primary Thermal Batteries," J. Electrochem. Soc., 163 [14] A3126-30 (2016).

32. K. Giagloglou, J. L. Payne, C. Crouch, R. K. B. Gover, P. A. Connor, and J. T. S. Irvine, "Synthesis and Electrochemical Study of $\mathrm{CoNi}_{2} \mathrm{~S}_{4}$ as a Novel Cathode Material in a Primary Li Thermal Battery,” J. Electrochem. Soc., 164 [9] A2159-63 (2017).

33. X. Zheng, Y. Zhu, Y. Sun, and Q. Jiao, "Hydrothermal Synthesis of $\mathrm{MoS}_{2}$ with Different Morphology and its Performance in Thermal Battery," J. Power Sources, 395 318-27 (2018).

34. K. Hasegawa and S. Noda, "Lithium Ion Batteries Made of Electrodes with $99 \mathrm{wt} \%$ Active Materials and $1 \mathrm{wt} \%$ Carbon Nanotubes without Binder or Metal Foils," J. Power Sources, 321 155-62 (2016). 
35. P. Sehrawat, C. Julien, and S. S. Islam, "Carbon Nanotubes in Li-Ion Batteries: A Review," Mater. Sci. Eng., B, 213 12-40 (2016).

36. I. Y. Kim, S. Y. Shin, J. H. Ko, K. S. Lee, S. P. Woo, D. K. Kim, and Y. S. Yoon, "Functional Li-M (Ti, Al, Co, Ni, Mn, Fe)-O Energy Materials," J. Korean Ceram. Soc., 54 [1] 922 (2017).

37. K. S. Lee, S. Y. Shin, and Y. S. Yoon, " $\mathrm{Fe}_{3} \mathrm{O}_{4}$ Nanoparticles on MWCNTs Backbone for Lithium Ion Batteries," $J$. Korean Ceram. Soc., 53 [3] 376-80 (2016).

38. J. H. Kim and D. K. Kim, "Conversion-Alloying Anode Materials for Na-Ion Batteries: Recent Progress, Challenges, and Perspective for the Future," J. Korean Ceram. Soc., 55 [4] 307-24 (2018).

39. T. Sadhasivam, M. J. Park, J. Y. Shin, J. E. Jin, S. C. Kim, M. D. Kurkuri, S. H. Roh, and H. Y. Jung, "High Charge Acceptance though Interface Reaction on Carbon Coated Negative Electrode for Advanced Lead-Carbon Battery System," Electrochim. Acta, 295 367-75 (2019).

40. J. Yin, N. Lin, W. Zhang, Z. Lin, Z. Zhang, Y. Wang, J. Shi, J. Bao, and H. Lin, "Highly Reversible Lead-Carbon Battery Anode with Lead Grafting on the Carbon Surface," J. Energy Chem., 27 1674-83 (2018).

41. W. Wang, Y. Liang, Y. Kang, L. Liu, Z. Xu, X. Tian, W. Mai, H. Fu, H. Lv, K. Teng, X. Jiao, and F. Li, "CarbonCoated $\mathrm{SnO}_{2} @$ Carbon Nanofibers Produced by Electrospinning-Electrospraying Method for Anode Materials of Lithium-Ion Batteries," Mater. Chem. Phys., 223 762-70 (2019).

42. H. Akbulut, D. Nalci, A. Guler, S. Duman, and M. O. Guler, "Carbon-Silicon Composite Anode Electrodes Modified with MWCNT for High Energy Battery Applications," Appl. Surf. Sci., 446 222-29 (2018).

43. Y. N. Lee, S. P. Woo, Y. S. Yoon, and S. H. Kim, "Significant Improvement in Reversibility of MWCNTs-Sn Compound Composite Electrode: Nanostructure Effect MWCNTSn Compound Composite on High Initial Reversible Capacity," J. Alloys Compd., 777 1098-107 (2019).

44. X. Yan, Y. Wang, T. Yu, H. Chen, Z. Zhao, and S. Guan, "Polyimide Binder by Combining with Polyimide Separator for Enhancing the Electrochemical Performance of Lithium Ion Batteries," Electrochim. Acta, 216 1-7 (2016).

45. J. Choi, M. H. Ryou, B. Son, J. Song, J. K. Park, K. Y. Cho, and Y. M. Lee, "Improved High-Temperature Performance of Lithium-Ion Batteries through Use of a Thermally Stable Co-Polyimide-based Cathode Binder," J. Power Sources, 252 138-43 (2014).

46. J. Liu, Q. Zhang, and Y. K. Sun, "Recent Progress of Advanced Binders for Li-S Batteries," J. Power Sources, 396 19-32 (2018).

47. M. Zheng, Y. Wang, J. Reeve, H. Souzandeh, and W. H. Zhong, "A Polymer-Alloy Binder for Structures-Properties Control of Battery Electrode," Energy Storage Mater., 14 149-58 (2018).

48. G. Hernandez, N. Lago, D. Shanmukaraj, M. Armand, and D. Mecerreyes, "Polyimide-Polyether Binder-Diminishing the Carbon Content in Lithium-Sulfur Batteries," Mater. Today Energy, 6 264-70 (2017).

49. J. Luis, G. Urbano, J. L. Gomez-Camer, C. Botas, and T.
Rojo, "Graphene Oxide-Carbon Nanotubes Aerogels with High Sulfur Loadings Suitable as Binder-free Cathodes for High Performance Lithium-Sulfur Batteries," J. Power Sources, 412 408-15 (2019).

50. L. Guo, H. Sun, C. Qin, W. Li, F. Wang, W. Song, J. Du, F. Zhong, and Y. Ding, "Flexible $\mathrm{Fe}_{3} \mathrm{O}_{4}$ Nanoparticles/Ndoped Carbon Nanofibers Hybrid Film as Binder-free Anode Materials for Lithium-Ion Batteries," Appl. Surf. Sci., 459 263-70 (2018).

51. Y. Liu, X.Chi, Q. Han, Y. Du, J. Yang, and Y. Liu, "Vertically Self-Standing $\mathrm{C} @ \mathrm{NiCo}_{2} \mathrm{O}_{4}$ Nanoneedle Arrays as Effective Binder-free Cathode for Rechargeable $\mathrm{Na}_{2} \mathrm{O}_{2}$ Batteries," J. Alloys Compd., 772 693-702 (2019).

52. J. Nong, P. Xie, A. S. Zhu, M. Z. Rong, and M. Q. Zhang, "Highly Conductive Doped Carbon Framework as Binderfree Cathode for Hybrid Li-O ${ }_{2}$ Battery," Carbon, 142 17789 (2019).

53. B. Li, Q. Xiao, and Y. Luo, "A Modified Synthesis Process of Three-Dimensional Sulfur/Graphene Aerogel as Binderfree Cathode for Lithium Sulfur Batteries," Mater. Des., 153 9-14 (2018).

54. T. G. Kim, E. Samuel, B. Joshi, C. W. Park, M. W. Kim, M. T. Swihart, W. Y. Yoon, and S. S. Yoon, "Supersonically Sprayed rGO- $\mathrm{Zn}_{2} \mathrm{Sn}_{4}$ Composites as Flexible, Binderfree, Scalable, and High-Capacity Lithium Ion Battery Anodes," J. Alloys Compd., 766 331-40 (2018).

55. C. C. Li and Y. W. Wang, "Binder Distributions in Waterbased and Organic-based $\mathrm{LiCoO}_{2}$ Electrode Sheets and their Effects on Cell Performance," J. Electrochem. Soc., 158 A $1361-70$ (2011).

56. M. Muller, L. Pfaffmann, S. Jaiser, M. Baunach, V. Trouillet, F. Scheiba, P. Scharfer, W. Schabel, and W. Bauer, "Investigation of Binder Distribution in Graphite Anodes for Lithium-Ion Batteries," J. Power Sources, 340 $1-5$ (2017).

57. B. Lestriez, "Functions of Polymers in Composite Electrodes of Lithium Ion Batteries," C. R. Chim., 13 [11] 1341-50 (2010).

58. S. L. Chou, Y. Pan, J. Z. Wang, H. K. Liu, and S. X. Dou, "Small Things Mask a Big Difference: Binder Effects on the Performance of $\mathrm{Li}$ and Na Batteries," Phys. Chem. Chem. Phys., 16 [38] 20347-59 (2014).

59. Z. Zhang, T. Zeng, Y. Lai, M. Jia, and J. Li, "A Comparative Study of Different Binders and Their Effects on Electrochemical Properties of $\mathrm{LiMn}_{2} \mathrm{O}_{4}$ Cathode in Lithium Ion Batteries," J. Power Sources, 247 1-8 (2014).

60. G. Liu, H. Zheng, X. Song, and V. S. Battaglia, "Particles and Polymer Binder Interaction: A Controlling Factor in Lithium-Ion Electrode Performance," J. Electrochem. Soc., 159 [3] A214-21 (2012).

61. S. H. Lee, C. Huang, C. Johnston, and P. S. Grant, "Spray Printing and Optimization of Anodes and Cathodes for High Performance Li-Ion Batteries," Electrochim. Acta, 292 546-57 (2018).

62. A. F. Leonard and N. Job, "Safe and Green Li-Ion Batteries based on $\mathrm{LiFePO}_{4}$ and $\mathrm{Li}_{4} \mathrm{Ti}_{5} \mathrm{O}_{12}$ Sprayed as Aqueous Slurries with Xanthan Gum as Common Binder," Mater. Today Energy, 12 168-78 (2019).

63. S. D. Kim, J. G. Lee, T. G. Kim, K. Rana, J. Y. Jeong, J. H. 
Park, S. S. Yoon, and J. H. Ahn, "Additive-free Electrode Fabrication with Reduced Graphene Oxide Using Supersonic Kinetic Spray for Flexible Lithium-Ion Batteries," Carbon, 139 195-204 (2018).

64. B. Joshi, E. Samuel, T. G. Kim, C. W. Park, Y. I. Kim, M. T. Swihart, W. Y. Yoon, and S. S. Yoon, "Supersonically Spray-Coated Zinc Ferrite/Graphitic-Carbon Nitride Composite as a Stable High-Capacity Anode Material for Lithium-Ion Batteries," J. Alloys Compd., 768 525-34 (2018).

65. H. Shi, S. Niu, W. Lv, G. Zhou, C. Zhang, Z. Sun, F. Li, F. Kang, and Q. H. Yang, "Easy Fabrication of Flexible and Multilayer Nanocarbon-based Cathodes with a High Unreal Sulfur Loading by Electrostatic Spraying for Lithium-Sulfur Batteries," Carbon, 138 18-25 (2018).

66. C. Y. Jung, T. S. Zhao, L. An, L. Zeng, and Z. H. Wei, "Screen Printed Cathode for Non-Aqueous Lithium-Oxygen Batteries," J. Power Sources, 297 174-80 (2015).

67. R. E. Sousa, J. Oliveira, A. Goren, D. Miranda, M. M. Silva, L. Hilliou, C. M. Costa, and S. Lanceros-Mendez, "High Performance Screen Printable Lithium-Ion Battery Cathode Ink based on C-LiFePO ${ }_{4}$, Electrochim. Acta, 196 92-100 (2016).

68. A. Goren, J. Mendes, H. M. Rodrigues, R. E. Sousa, J. Oliveira, L. Hilliou, C. M. Costa, M. M. Silva, and S. Lanceros-Mendez, "High Performance Screen-Printed Electrodes Prepared by a Green Solvent Approach for Lithium-Ion Batteries,” J. Power Sources, 334 65-77 (2016).

69. K. Y. Kang, Y. G. Lee, D. O. Shin, J. C. Kim, and K. M. Kim, "Performance Improvements of Pouch-Type Flexible Thin-Film Lithium-Ion Batteries by Modifying Sequential Screen Printing Process," Electrochim. Acta, 138 294-301 (2014).

70. Z. Tehrani, T. Korochkina, S. Govindarajan, D. J. Thomas, J. O’Mahony, J. Kettle, T. C. Claypole, and D. T. Gethin, "Ultra-Thin Flexible Screen Printed Rechargeable Polymer Battery for Wearable Electronic Applications," Org. Electron., 26 386-94 (2015).

71. B. Bitsch, J. Dittmann, M. Schmitt, P. Scharfer, W. Schabel, and N. Willenbacher, "A Novel Slurry Concept for the Fabrication of Lithium-Ion Battery Electrodes with Beneficial Properties," J. Power Sources, 265 81-90 (2014).

72. A. Ponrouch and M. R. Palacin, "On the Impact of the Slurry Mixing Procedure in the Electrochemical Performance of Composite Electrodes for Li-Ion Batteries: A Case Study for Mesocarbon Microbeads (MCMB) Graphite and $\mathrm{Co}_{3} \mathrm{O}_{4}$," J. Power Sources, 196 9682-88 (2011).

73. K. Y. Cho, Y. I. Kwon, J. R. Youn, and Y. S. Song, "Evaluation of Slurry Characteristics for Rechargeable LithiumIon Batteries," Mater. Res. Bull., 48 [8] 2922-26 (2013).

74. W. Bauer and D. Notzel, "Rheological Properties and Stability of NMP Based Cathode Slurries for Lithium Ion Batteries," Ceram. Int., 40 [3] 4591-98 (2014).

75. K. Okubo, H. Wang, K. Hayashi, M. Inada, N. Enomoto, G. Hasegawa, T. Osawa, and H. Takamura, "A Dense NASICON Sheet Prepared by Tape-Casting and Low Temperature Sintering," Electrochim. Acta, 278 176-81 (2018).

76. A. Rincon, R. Moreno, A. S. A. Chinelatto, C. F. Gutierrez, E. Rayon, M. D. Salvador, and A. Borrell, " $\mathrm{Al}_{2} \mathrm{O}_{3}-3 \mathrm{YTZP}$ -
Graphene Multilayers Produced by Tape Casting and Spark Plasma Sintering," J. Eur. Ceram. Soc., 34 [10] 2427-34 (2014).

77. M. R. Somalu, A. Muchtar, W. R. W. Daud, and N. P. Brandon, "Screen-Printing Inks for the Fabrication of Solid Oxide Fuel Cell Films: A Review," Renewable Sustainable Energy Rev., 75 426-39 (2017).

78. W. Wang, S. Chen, J. Li, and W. Wang, "Fabrication of Catalyst Coated Membrane with Screen Printing Method in a Proton Exchange Membrane Fuel Cell," Int. J. Hydrogen Energy, 40 [13] 4649-58 (2015).

79. E. F. Mine, Y. Ito, Y. Teranishi, M. Sato, and T. Shimizu, "Surface Coating and Texturing on Stainless-Steel Plates to Decrease the Contact Resistance by Using Screen Printing," Int. J. Hydrogen Energy, 42 [31] 20224-29 (2017).

80. D. H. Lee, J. S. Choi, H. Chae, C. H. Chung, and S. M. Cho," Highly Efficient Phosphorescent Polymer OLEDs Fabricated by Screen Printing," Displays, 29 [5] 436-39 (2008).

81. S. Ohta, S. Komagata, J. Seki, T. Saeki, S. Morishita, and T. Asaoka, "All-Solid-State Lithium Ion Battery Using Garnet-Type Oxide and $\mathrm{Li}_{3} \mathrm{BO}_{3}$ Solid Electrolytes Fabricated by Screen-Printing," J. Power Sources, 238 53-6 (2013).

82. T. Syrovy, T. Kazda, L. Syrova, J. Vondrak, L. Kubac, and M. Sedlarikova, "Cathode Material for Lithium Ion Accumulators Prepared by Screen Printing for Smart Textile Applications,” J. Power Sources, 309 192-201 (2016).

83. M. H. Sayed, E. V. G. Robert, P. J. Dale, and L. Gutay, " $\mathrm{Cu}_{2} \mathrm{SnS}_{3}$ Based Thin Film Solar Cells from Chemical Spray Pyrolysis," Thin Solid Films, 669 436-39 (2019).

84. Z. Liang, Z. Bi, K. Gao, Y. Fu, P. Guan, X. Feng, Z. Chai, G. $\mathrm{Xu}$, and $\mathrm{X}$. $\mathrm{Xu}$, "Interface Modification via $\mathrm{Al}_{2} \mathrm{O}_{3}$ with Retarded Charge Recombination for Mesoscopic Perovskite Solar Cells Fabricated with Spray Deposition Process in the Air," Appl. Surf. Sci., 463 939-46 (2019).

85. K. Y. Bae, M. W. Kim, B. H. Kim, S. H. Cho, S. S. Yoon, and W. Y. Yoon, "Effect of Electrostatic Spray Deposited Nafion Coating on Non-Lithiated $\mathrm{LiV}_{3} \mathrm{O}_{8}$ Cathode in Lithium-Metal Rechargeable Batteries," Solid State Ionics, 331 66-73 (2019).

86. X. Wu, F. Li, W. Wu, and T. Guo, "Flexible Organic Light Emitting Diodes Based on Double-Layered Graphene/ PEDOT:PSS Conductive Film Formed by Spray-Coating," Vacuum, 101 53-6 (2014).

87. A. Falco, A. M. Zaidi, P. Lugli, and A. Abdellah, "Spray Deposition of Polyethylenimine Thin Films for the Fabrication of Fully-Sprayed Organic Photodiodes," Org. Electron., 23 186-92 (2015).

88. T. Bayer, R. Selyanchyn, S. Fujikawa, K. Sasaki, and S. M. Lyth, "Spray-Painted Graphene Oxide Membrane Fuel Cells," J. Membr. Sci., 541 347-57 (2017).

89. A. B. Tahar, A. Romdhane, N. Lalaoui, N. Reverdy-Bruas, A. L. Goff, M. Holzinger, S. Cosnier, D. Chaussy, and N. Belgacem, "Carbon Nanotube-based Flexible Biocathode for Enzymatic Biofuel Cells by Spray Coating," J. Power Sources, 408 1-6 (2018).

90. Q. Guo, P. Guo, J. Li, H. Yin, J. Liu, F. Xial, D. Shen, and 
N. Li, " $\mathrm{Fe}_{3} \mathrm{O}_{4}$-CNTs Nanocomposites: Inorganic Dispersant Assisted Hydrothermal Synthesis and Application in Lithium Ion Batteries," J. Solid State Chem., 213 104-9 (2014).

91. Q. Liu, Q. Jiang, L. Jiang, J. Peng, Y. Gao, Z. Duan, and X. Lu, "Preparation of $\mathrm{SnO}_{2} @ \mathrm{rGO} / \mathrm{CNT} / \mathrm{S}$ Composite and Application for Lithium-Sulfur Battery Cathode Material," Appl. Surf. Sci., 462 393-98 (2018).

92. M. Kazazi, Z. A. Zafar, M. Delshad, J. Cervenka, and C. Chen, " $\mathrm{TiO}_{2} / \mathrm{CNT}$ Nanocomposite as an Improved Anode Material for Aqueous Rechargeable Aluminum Batteries," Solid State Ionics, 320 64-9 (2018).

93. M. Y. Son, J. H. Choi, and Y. C. Kang, "Electrochemical Properties of Bare Nickel Sulfide and Nickel Sulfide-Carbon Composite Prepared by One-Pot Spray Pyrolysis as Anode Materials for Lithium Secondary Batteries," $J$. Power Sources, 251 480-87 (2014).

94. Y. Yamaguchi, T. Takeuchi, H. Sakaebe, H. Kageyama, H. Senoh, T. Sakai, and K. Tatsumi, "Ab Initio Simulations of Li/Pyrite- $\mathrm{MS}_{2}(\mathrm{M}=\mathrm{Fe}, \mathrm{Ni})$ Battery Cells," J. Electrochem. Soc., 157 [6] A630-35 (2010).

95. A. A. AbdelHamid, X. Yang, J. Yang, X. Chen, and J. Y. Ying, "Graphene-Wrapped Nickel Sulfide Nanoprisms with Improved Performance for Li-Ion Battery Anodes and Supercapacitors," Nano Energy, 26 425-37 (2016).

96. T. Takeuchi, H. Sakaebe, H. Kageyama, T. Sakai, and K. Tatsumi, "Preparation of $\mathrm{NiS}_{2}$ Using Spark-Plasma-Sintering Process and its Electrochemical Properties," J. Electrochem. Soc., 155 [9] A679-84 (2008).

97. S. W. Oh, S. T. Myung, S. M. Oh, K. H. Oh, K. Amine, B. Scrosati, and Y. K. Sun, "Double Carbon Coating of LiFe$\mathrm{PO}_{4}$ as High Rate Electrode for Rechargeable Lithium
Batteries," Adv. Mater., 22 [43] 4842-45 (2010).

98. X. Zhang, X. Zhang, X. G. Wang, Z. Xie, and Z. Zhou, " $\mathrm{NiFe}_{2} \mathrm{O}_{4}$-CNT Composite: An Efficient Electrocatalyst for Oxygen Evolution Reactions in $\mathrm{Li}-\mathrm{O}_{2}$ Batteries Guided by Computations," J. Mater. Chem. A, 4 [24] 9390-93 (2016).

99. J. Yang, Y. Ouyang, H. Zhang, H. Xu, Y. Zhang, and Y. Wang, "Novel $\mathrm{Fe}_{2} \mathrm{P} /$ Graphitized Carbon Yolk/Shell Octahedral for High-Efficiency Hydrogen Production and Lithium Storage," J. Mater. Chem. A, 4 [25] 9923-30 (2016).

100. Z. Liu, T. Lu, T. Song, X. Y. Yu, X. W. Lou, and U. Paik, "Structure-Designed Synthesis of $\mathrm{FeS}_{2} @ \mathrm{C}$ Yolk-Shell Nanoboxes as a High-Performance Anode for Sodium-Ion Batteries," Energy Environ. Sci., 10 [7] 1576-80 (2017).

101. Y. Li, Y. S. Hu, M. M. Titirici, L. Chen, and X. Huang, "Hard Carbon Microtubes Made from Renewable Cotton as High-Performance Anode Material for Sodium-Ion Batteries," Adv. Energy Mater., 6 [18] 1600659 (2016).

102. J. Shan, Y. Liu, Y. Su, P. Liu, X. Zhuang, D. Wu, F. Zhang, and X. Feng, "Graphene-Directed Two-Dimensional Porous Carbon Frameworks for High-Performance Lithium-Sulfur Battery Cathodes," J. Mater. Chem. A, 4 [1] 314-20 (2016)

103. Y. Sakurai, H. Ohtsuka, and J. Yamaki, "Rechargeable Copper Vanadate Cathode for Lithium Cell," J. Electrochem. Soc., 135 [1] 32-6 (1988).

104. M. Eguchi, A. Komamura, T. Miuru, and T. Kishi, "Lithiation Characteristics of $\mathrm{Cu}_{5} \mathrm{~V}_{2} \mathrm{O}_{10}$, J. Electrochim. Acta, 41 [6] 857-61 (1996)

105. F. Gao, J. Shi, H. Liu, S. Qiang, L. Gao, S. Bi, and W. Liu, "A Novel and Safety Lithium Thermal Battery Electrolyte - $\mathrm{Li}_{7} \mathrm{La}_{3} \mathrm{Zr}_{2} \mathrm{O}_{12}$ Prepared by Solid State Method," Solid State Ionics, 326 131-35 (2018). 